\title{
Measurement of Directional Wave Spectra Using Aircraft Laser Altimeters
}

\author{
J. Sun, ${ }^{*}$ S. P. Burns, ${ }^{*}$ D. VAndemark, ${ }^{+}$M. A. Donelan, ${ }^{\#}$ L. Mahrt, ${ }^{@}$ Timothy L. Crawford, \&,@@ \\ T. H. C. Herbers, ${ }^{* *}$ G. H. CRescentI ${ }^{++}$and J. R. French \#\# \\ *National Center for Atmospheric Research, Boulder, Colorado \\ ${ }^{+}$NASA Goddard Space Flight Center, Wallops Island, Virginia \\ \#RSMAS/Applied Marine Physics, University of Miami, Miami, Florida \\ @ College of Oceanic and Atmospheric Sciences, Oregon State University, Corvallis, Oregon \\ \&NOAA/ARL/Field Research Division, Idaho Falls, Idaho \\ **Department of Oceanography, Naval Postgraduate School, Monterey, California \\ ++ FLP Energy, Juno Beach, Florida \\ \#\# National Oceanic and Atmospheric Administration, Oak Ridge, Tennessee
}

(Manuscript received 10 July 2003, in final form 16 August 2004)

\begin{abstract}
A remote sensing method to measure directional oceanic surface waves by three laser altimeters on the NOAA LongEZ aircraft is investigated. To examine feasibility and sensitivity of the wavelet analysis method to various waves, aircraft motions, and aircraft flight directions relative to wave propagation directions, idealized surface waves are simulated from various idealized aircraft flights. In addition, the wavelet analysis method is also applied to two cases from field measurements, and the results are compared with traditional wave spectra from buoys. Since the wavelet analysis method relies on the "wave slopes" measured through phase differences between the time series of the laser distances between the aircraft and sea surface at spatially separated locations, the resolved directional wavenumber and wave propagation direction are not affected by aircraft motions if the resolved frequencies of the aircraft motion and the wave are not the same. However, the encounter wave frequency, which is directly resolved using the laser measurement from the moving aircraft, is affected by the Doppler shift due to aircraft motion relative to wave propagations. The wavelet analysis method could fail if the aircraft flies in the direction such that the aircraft speed along the wave propagation direction is the same as the wave phase speed (i.e., the aircraft flies along wave crests or troughs) or if two waves with different wavelengths and phase speed have the same encountered wavelength from the aircraft. In addition, the data noise due to laser measurement uncertainty or natural isotropic surface elevation perturbations can also affect the relative phase difference between the laser distance measurements, which in turn affects the accuracy of the resolved wavenumber and wave propagation direction. The smallest waves measured by the lasers depend on laser sampling rate and horizontal distances between the lasers (for the LongEZ this is $2 \mathrm{~m}$ ). The resolved wave direction and wavenumber at the peak wave from the two field experiments compared well with on-site buoy observations. Overall, the study demonstrates that three spatially separated laser altimeters on moving platforms can be utilized to resolve two-dimensional wave spectra.
\end{abstract}

\section{Introduction}

Understanding the coupling between the sea and the atmosphere continues to be one of the important and unsolved problems in marine boundary layer research.

@@Deceased.

Corresponding author address: Dr. Jielun Sun, NCAR/MMM, P.O. Box 3000, 3450 Mitchell Lane, Boulder, CO 80307-3000. E-mail: jsun@ucar.edu
Traditional methods of estimating wave spectra rely on assumed wave spectral formula and parameter-fitting based on single-point (Longuet-Higgins et al. 1963; Long and Hasselmann 1979; Long 1980; Hasselmann et al. 1980) or array measurements with various constraints (Capon 1969; Davis and Regier 1977; Pawka 1983; Oltman-Shay and Guza 1984; Herbers and Guza 1990). Over the years, directional wave distribution models were developed to correlate surface stress with surface wave spectra. Recent investigations of nonstationary characteristics of wind waves (Liu 2000a,b) emphasize the importance of collocated, high-resolution 
measurements of both wave fields and the atmospheric state immediately above the waves.

Remote sensing has been used to measure wave field characteristics for many decades. Cox and Munk (1954) used sun glitter to observe oceanic wave patterns. With developments of radar, laser, and acoustic technology, directional wave spectra have been derived in various field experiments, which demonstrate the ability to map wave fields for an area (Beal et al. 1986; Walsh et al. 1985, 1989; Krogstad et al. 1988; Trevorrow and Booth 1995; Wyatt 1995; Hwang 1995; Frasier et al. 1995; Hwang et al. 2000a,b,c).

Simultaneous measurements of surface waves and atmospheric turbulence are commonly available from buoys. The Southern Ocean Waves Experiment is believed to be the first experiment in which simultaneous airborne measurements of surface waves and atmospheric turbulence were made (Banner et al. 1999; Chen et al. 2001). The National Oceanic and Atmospheric Administration (NOAA) LongEZ research aircraft (Crawford et al. 2001; Crescenti et al. 2002) was equipped with three laser altimeters for measurements of surface elevation, in addition to its traditional atmospheric turbulence measurements during the Shoaling Waves Experiment (SHOWEX) and the Coupled Boundary Layer Air-Sea Transfer experiment under weak winds (CBLAST-Low). The data from the three laser altimeters on the LongEZ have been utilized to calculate mean square slopes of long waves in Sun et al. (2001) and Vandemark et al. (2001). The ability to simultaneously measure atmospheric turbulence and surface waves demonstrated by the LongEZ during SHOWEX provides a desirable platform to investigate air-sea interactions over large areas, especially with spatially varying wave fields.

In this study, we investigate two-dimensional (2D) wave spectra using the three laser altimeters on board the LongEZ aircraft. The methodology to resolve directional wave spectra and its sensitivity to various aircraft maneuvers for idealized wave fields are described in section 2. The laser altimeters and the application of the method to two cases from two field experiments are illustrated in section 3. Concluding remarks are given in section 4.

\section{Wavelet analysis method of directional wave}

\section{a. Derivation of wavenumber and wave propagation direction}

A recent overview of oceanic surface wave spectra was given by Huang et al. (2001). In this study, twodimensional wave spectra are calculated using the Morlet wavelet directional wave analysis described in
Donelan et al. (1996). Traditional Fourier decomposition is based on a global basis set, whereas wavelet basis sets are local. In general, a time series, $f(t)$, can be expressed in terms of the wavelet function $\psi_{\lambda, u}(t)$, as (Farge 1992; Kumar and Foufoula-Georgiou 1994; Torrence and Compo 1998)

$$
f(t)=\frac{1}{C_{\psi}} \iint \lambda^{-2}\left\langle f, \psi_{\lambda, u}\right\rangle \psi_{\lambda, u}(t) d \lambda d u,
$$

where

$$
\begin{aligned}
\left\langle f, \psi_{\lambda, t}\right\rangle & =\iint f(u) \psi_{\lambda, u}(t) d u, \\
& =\iint f(u) \frac{1}{\sqrt{\lambda}} \psi\left(\frac{u-t}{\lambda}\right) d u ; \\
C_{\psi} & =2 \pi \int \frac{|\hat{\psi}(\omega)|^{2}}{\omega} d \omega,
\end{aligned}
$$

and $\lambda$ and the caret $\left({ }^{\wedge}\right)$ represent the wavelet scale and the Fourier transform, respectively. In this study, we use the Morlet wavelet,

$$
\psi(\eta)=e^{i \tilde{\omega} \eta} e^{-\frac{\eta^{2}}{2}},
$$

which represents a group of sine waves with amplitudes confined by a bell-shaped function $e^{-\eta^{2} / 2}$. The frequency of the sine waves, $\tilde{\omega}$, is predefined. In this study, $\tilde{\omega}$ is chosen to be approximately $5.4 \mathrm{rad} \mathrm{s}^{-1}$. In addition, we choose the width of the bell shape to be controlled by a wavelet scale $\left(s_{j}\right)$ and the wavelet transform to be moved along the time series (controlled by $k$ ). Therefore, $u$ and $\lambda$ in Eq. (1) can be written as

$$
\begin{aligned}
& \lambda=s_{j}, \\
& \frac{u}{\lambda}=k .
\end{aligned}
$$

The wavelet scale $s_{j}$ is chosen to be $s_{j}=2^{-(j+q / Q)}$, where $j=-4,-3, \ldots, 4$ to represent the $j$ th wavelet scale. To increase resolution of the wavelet scales, $q=0,1, \ldots$, $Q$, where the number of voices $Q=4$ is used. Substituting Eqs. (5) and (6) into Eqs. (1) and (2), we have

$$
\begin{aligned}
f(t) & =\frac{1}{C_{\psi}} \iint s_{j}^{-3 / 2}\left\langle f, \psi_{s_{j}, k}\right\rangle \psi\left(k-\frac{t}{s_{j}}\right) d s_{j} d k, \\
\left\langle f, \psi_{s_{j}, t}\right\rangle & =\iint \sqrt{s_{j}} f\left(s_{j} k\right) \psi\left(k-\frac{t}{s_{j}}\right) d k .
\end{aligned}
$$

In this study, we focus on derivation of $2 \mathrm{D}$ wave directional spectra from simultaneous measurements of the distance between the ocean surface and the aircraft using three onboard laser altimeters (section 3). On the LongEZ, the three lasers are separated horizontally on 


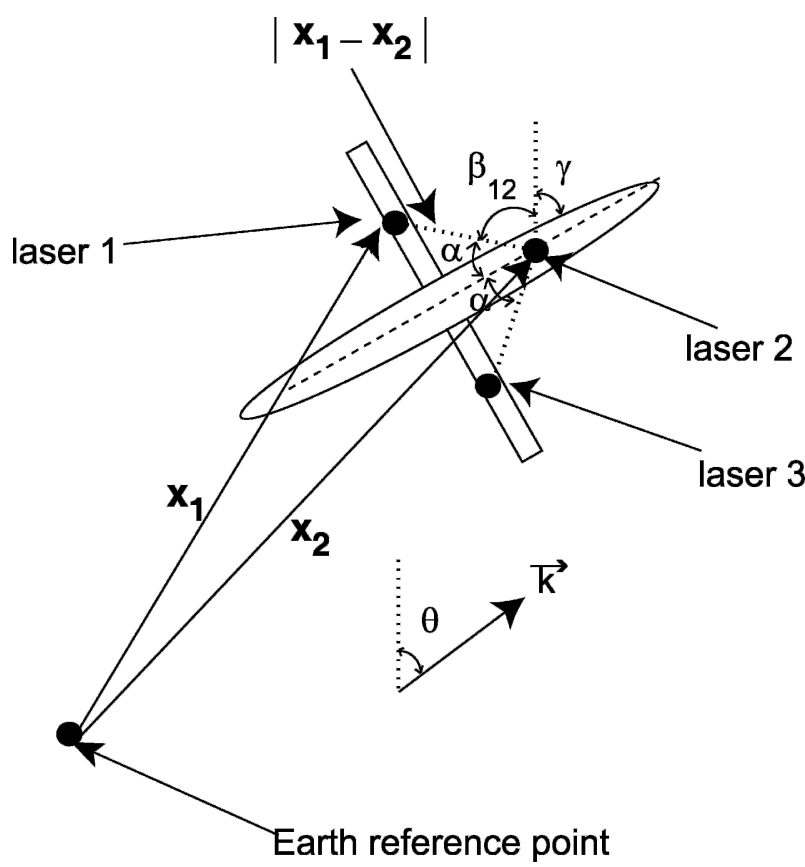

FIG. 1. Schematic of the three laser altimeters on board the LongEZ aircraft and the wavenumber vector in the earth coordinates. Here $\gamma$ is the aircraft heading, and $\alpha$ is the angle between the line through lasers 1 and $2\left(\mathbf{x}_{1}-\mathbf{x}_{2}\right)$ and the aircraft centerline (dashed line). Lasers 1 and 3 are symmetric around the aircraft central line. The dimensions are listed in Fig. 9.

the aircraft plane in a shape of an equilateral triangle (Fig. 1). Lasers 1 and 3 are symmetrically mounted beneath the two wings of the aircraft, and laser 2 is mounted along the aircraft centerline. The three lasers simultaneously sample surface at a constant rate. For simplicity, we assume that the three laser beams are perpendicular to the averaged sea surface plane and that the aircraft flies at a constant speed. On the LongEZ aircraft, the three laser beams are aligned approximately perpendicular to the averaged sea surface during most level flights; that is, the pitch angle of the aircraft is not zero. Complications related to the aircraft roll and pitch motions are discussed later in this section.

By applying the above wavelet analysis to the time series of the three laser distances collected from the aircraft, oceanic waves can be decomposed into wavelet scales, which represent frequencies observed by the aircraft, or encounter frequencies. The wavelet analysis method uses wavelet scales to represent the wave frequency. Similarities and differences between the Fourier and wavelet spectra were investigated by Howell and Mahrt (1997). Notice that due to aircraft motion this encounter frequency is different from the true frequency of waves observed at a fixed location; that is, the encounter frequency is relative to the aircraft mov- ing coordinates and is what the aircraft "sees." For a plane wave, such as $\exp [i(\mathbf{k} \cdot \mathbf{x}-\omega t)]$, where $\mathbf{x}$ is the location of a laser relative to the earth and can be expressed as

$$
\mathbf{x}=\mathbf{a}+\mathbf{V}_{a} t .
$$

Here $\mathbf{a}$ is the location of the laser in the aircraft coordinates, and $\mathbf{V}_{a}$ is the aircraft velocity in the earth coordinates. In this case, the corresponding wave phase is

$$
\phi=\mathbf{k} \cdot \mathbf{a}-\left(\omega-\mathbf{V}_{a} \cdot \mathbf{k}\right) t
$$

and the encounter frequency, $\omega_{e}$, is

$$
\omega_{e}=\omega-\mathbf{V}_{a} \cdot \mathbf{k},
$$

which is Doppler shifted due to the aircraft motion. The wave spectra at high frequency can also be Doppler shifted due to orbital displacements (Kitaigordskii et al. 1975).

At any instantaneous time, the three lasers sample the same surface waves at three intersections between the lasers and the sea surface. The measured distance differences from the three lasers at any instantaneous time reflect the wave slope. Therefore, at each encounter frequency the time series of the surface elevation from three laser measurements can be expressed with the same wave amplitude but different wave phase at any time $t$. The phase difference between the $i$ th and $j$ th lasers at each encounter frequency can be expressed as

$$
\phi_{i, j}=\mathbf{k} \cdot \mathbf{x}_{i, j},
$$

where $\mathbf{k}$ is the wavenumber vector of oceanic surface waves, and $\mathbf{x}_{i, j}$ is the horizontal distance between two lasers. In the earth polar coordinates, $\mathbf{k}$ and $\mathbf{x}_{i, j}$ can be expressed as

$$
\begin{aligned}
\mathbf{k} & =(k, \theta), \\
\mathbf{x}_{i, j} & =\left(\left|\mathbf{x}_{i}-\mathbf{x}_{j}\right|, \beta_{i, j}\right),
\end{aligned}
$$

where $k$ is the wavenumber, $\theta$ is the wave propagation direction from the north, and $\beta_{i, j}$ is the angle between $\mathbf{x}_{i}-\mathbf{x}_{j}$ and the north in the earth coordinates. Based on Fig. 1,

$$
\begin{aligned}
& \beta_{12}=180^{\circ}-\gamma-\alpha, \\
& \beta_{23}=180^{\circ}-\gamma+\alpha,
\end{aligned}
$$

where $\gamma$ is the aircraft heading from the north in the earth coordinates, and $\alpha$ is the angle between $\mathbf{x}_{1}-\mathbf{x}_{2}$ and the aircraft centerline (Fig. 1). In this study, $\mid \mathbf{x}_{1}-$ $\mathbf{x}_{2}|=| \mathbf{x}_{2}-\mathbf{x}_{3} \mid \equiv r=0.93 \mathrm{~m}$. Based on Eq. (12), two equations can be generated from three lasers:

$$
\begin{aligned}
& \phi_{12}=\mathbf{k} \cdot\left(\mathbf{x}_{1}-\mathbf{x}_{2}\right)=k r \cos \left(\theta-\beta_{12}\right), \\
& \phi_{23}=\mathbf{k} \cdot\left(\mathbf{x}_{2}-\mathbf{x}_{3}\right)=k r \cos \left(\theta-\beta_{23}\right) .
\end{aligned}
$$


The wavenumber $k$, and the wave propagation direction, $\theta$, can be derived from the above two equations as

$$
\begin{aligned}
\theta= & \arctan \left[\left(\phi_{12} \cos \beta_{23}-\phi_{23} \cos \beta_{12}\right) /\left(\phi_{23} \sin \beta_{12}\right.\right. \\
& \left.\left.-\phi_{12} \sin \beta_{23}\right)\right], \\
k= & \phi_{12} /\left[r \cos \left(\theta-\beta_{12}\right)\right] .
\end{aligned}
$$

Notice that to derive the wavenumber and wave propagation direction from the aircraft time series of the surface elevation, only the aircraft heading is needed.

The above methodology is identical to the one used in Donelan et al. (1996), except that the application here is for aircraft measurements instead of tower measurements. If the surface elevation is sampled at a constant spatial interval as a spatial series at any instantaneous time, the wavenumber can be derived from the frequency spectra of the spatial series. Since the aircraft flies much faster than oceanic waves propagate, the time series of the surface elevation sampled from the aircraft is approximately the spatial series of the surface elevation. The approximation depends on how fast the aircraft flies relative to the speed at which wave propagates, that is, the Doppler shift. Notice that the wave propagation direction and wavenumber in Eqs. (19) and (20) are not derived from the encounter frequency spectra based on the surface elevation measurement but the phase difference between the three lasers at each encounter frequency. Therefore, the derived wavenumber and wave propagation direction are not subject to Doppler shift, but the encounter wave frequency is. If the aircraft rolls or pitches, the measured distance is not only the difference between the surface elevation and the aircraft flight height but also the difference between the laser sensor and the aircraft horizontal plane. Therefore, the aircraft motion causes phase differences at the encounter frequency of the aircraft motion. However, the phase difference at the encounter wave frequency is not contaminated by such errors, if the encounter wave frequency is different from the encounter frequency of the aircraft motion. Therefore, the true wavenumber can be solved by focusing on the encounter wave frequency associated with the wave. In other words, the laser distance measurement does not need to be corrected for the aircraft motion if the frequency of the aircraft motion is different from the encounter wave frequency. This concept is crucial for the success of the wave measurement from any moving platform using the laser altimeter technique.

For tower measurements at a fixed location, the wave frequency as well as wavenumber can be derived from the time series of the surface elevation sampled at a constant rate without any Doppler correction. There- fore, the linear dispersion relationship can be examined by using independent tower measurements of wave frequency and wavenumber derived from the wavelet analysis method. However, to obtain the true wave frequency using the aircraft laser data, the encounter frequency needs to be corrected for varying aircraft speed and fluctuations of the aircraft track from a straight horizontal line. Therefore, the linear dispersion relationship between wavenumber and wave frequency cannot be examined by using the aircraft laser data until the encounter frequency is corrected to yield the estimated wave frequency. Although the advantage of the wavelet method is its ability to capture wave groups, in this study we focus on the statistics of surface waves measured by the aircraft along a level run.

\section{b. Sensitivity test of the wavelet analysis method}

To test the methodology several idealized waves are used and sampled as they would be sampled by an aircraft. Three monochromatic waves, with wave properties listed in Table 1, are chosen to represent typical swell and wind waves. The linear dispersion relationship at an arbitrary water depth of $100 \mathrm{~m}$ is selected. Wave fields, which consist of an individual single sine wave (wave1, wave2, or wave3) and two mixed waves [wave1 and wave2 (two long waves) or wave1 and wave3 (a long and a short wave)], are adopted to test the sensitivity of the wavelet analysis method to the aircraft heading relative to the wave propagation. The aircraft heading is assumed to vary from $0^{\circ}$ to $360^{\circ}$ at $10^{\circ}$ increments. Assuming the aircraft flies at $\mathbf{v}_{a}=50$ $\mathrm{m} \mathrm{s}^{-1}$ and samples surface elevation at the sampling rate of $50 \mathrm{~s}^{-1}$ from three laser altimeters, the measured distances from the three lasers are used to test the wavelet analysis method. The configuration of the three laser altimeters employed in the sensitivity test is the same as the one on the LongEZ aircraft, which is described in section $3 \mathrm{a}$.

First we assume that there is no random noise in the measured surface elevation, and the aircraft flies in a straight line with no aircraft roll and pitch motions. Three time series of the surface elevation are sampled

TABLE 1. Monochromatic wave properties.

\begin{tabular}{lcccc}
\hline \hline & $\begin{array}{c}\text { Wave } \\
\text { Wavelength } \\
(\mathrm{m})\end{array}$ & $\begin{array}{c}\text { propagation } \\
\text { direction } \\
\left({ }^{\circ} \text { from north }\right)\end{array}$ & $\begin{array}{c}\text { Wave phase } \\
\text { speed } \\
\left(\mathrm{m} \mathrm{s}^{-1}\right)\end{array}$ & $\begin{array}{c}\text { Wave } \\
\text { amplitude } \\
(\mathrm{m})\end{array}$ \\
\hline Wave1 & 156 & 90 & 15.6 & 2.5 \\
Wave2 & 70 & 60 & 10.5 & 2 \\
Wave3 & 20 & 30 & 5.6 & 1 \\
\hline
\end{tabular}




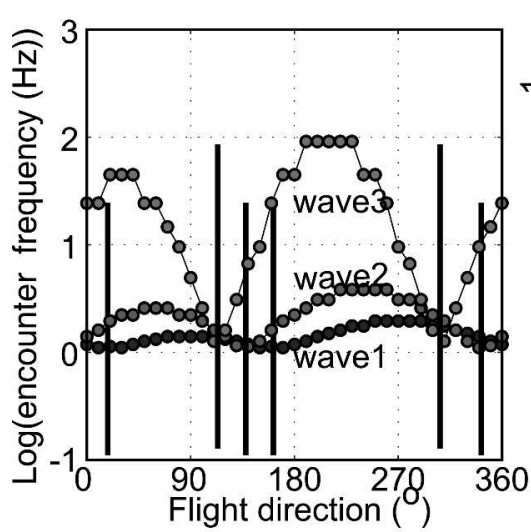

(a) Clean single sine waves
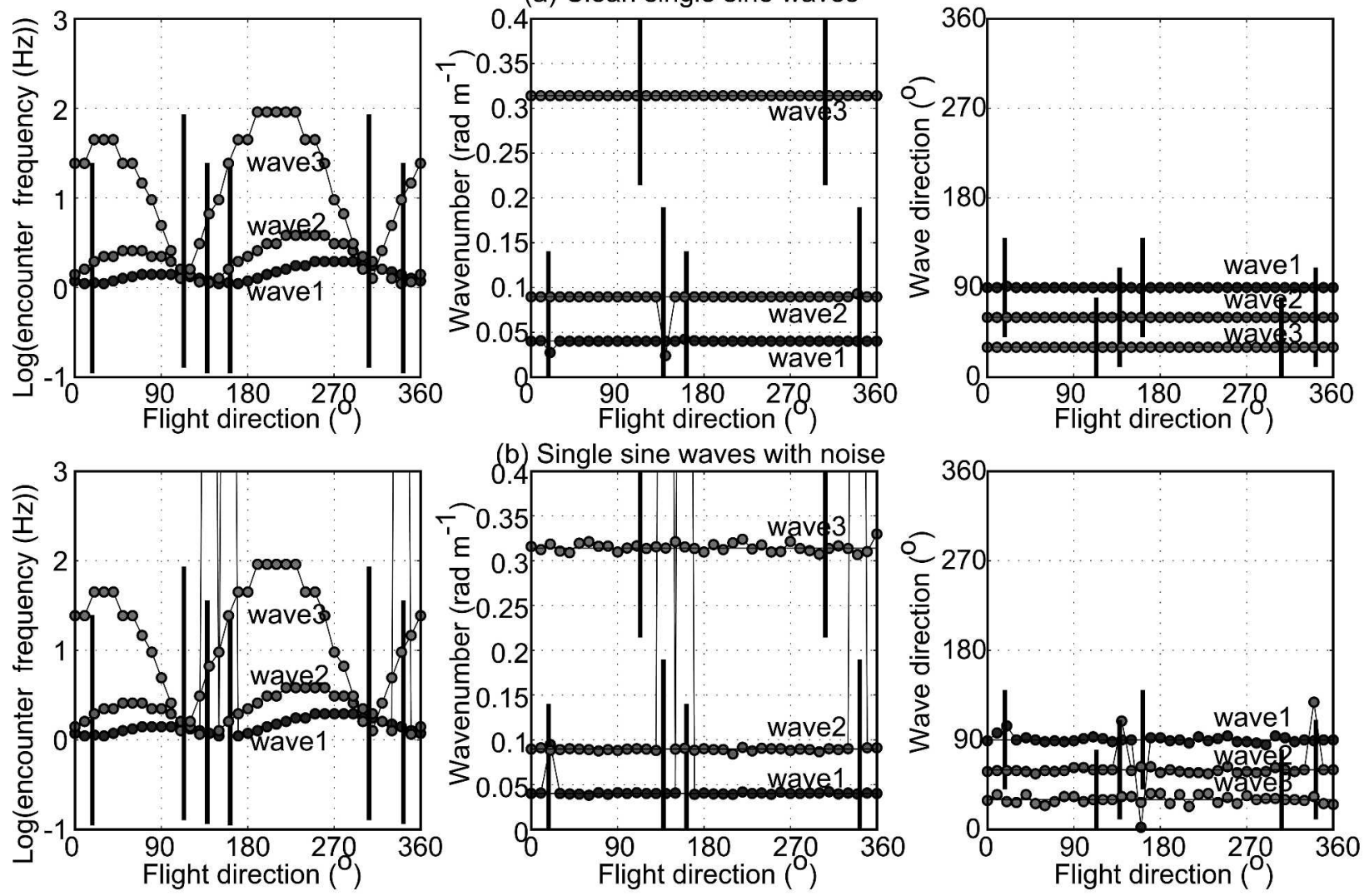

(c) Single sine waves with aircraft roll motion
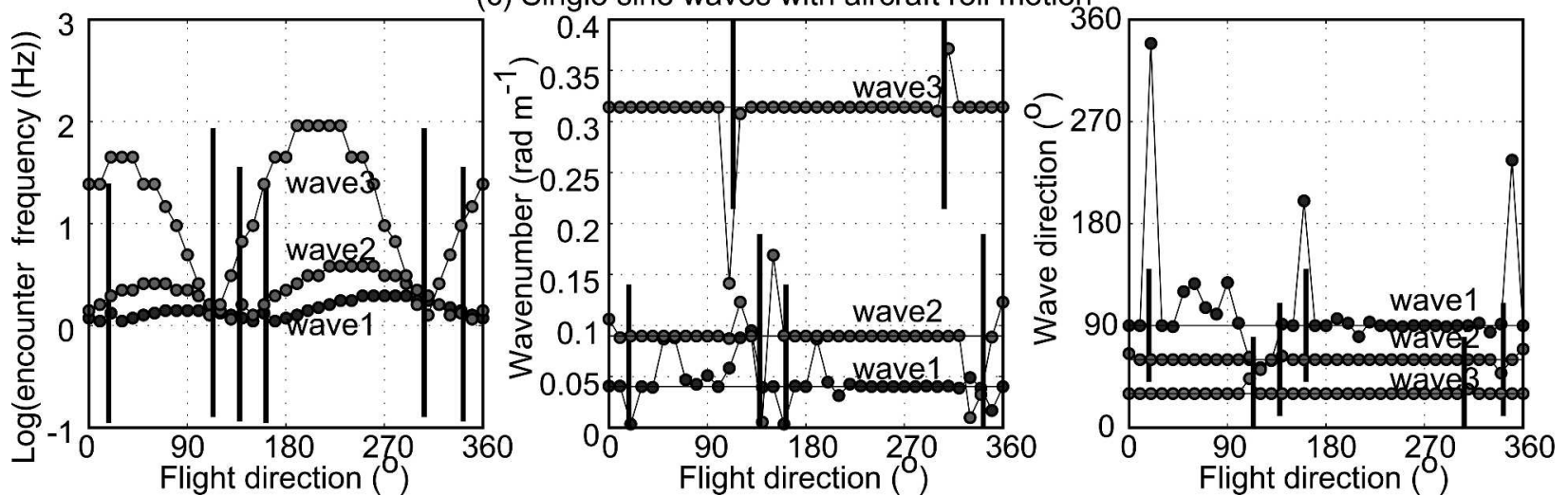

FIG. 2. Three rows demonstrate the encounter peak wave frequency, wavenumber, and wave propagation direction from the north as a function of the aircraft heading for the three individual, idealized single wave fields. (a) The test for the single perfect sine waves. (b) The test for the single sine waves with the noise of $5 \%$ of wave 3 amplitude. (c) The test for the single perfect sine waves with the aircraft roll motion of $\omega_{\text {roll }}=1 \mathrm{rad} \mathrm{s}^{-1}$. The thick vertical lines are the flight directions when $\mathbf{v}_{a}^{\|}=\mathbf{c}_{p}$.

as they would be from the three lasers on board the LongEZ aircraft. By applying the wavelet analysis, the wave energy density peaks at an encounter frequency. The wavenumber and the wave propagation direction at the encountered peak frequency agree well with the designed wave field (Fig. 2). Figure 2a demonstrates that the wavenumber and wave propagation direction for the single monochromatic waves can be resolved perfectly except when the aircraft flies close to the direction where the aircraft travel speed along the wave propagation direction is the same as the wave phase speed $\left(\mathbf{c}_{p}\right)$ Mathematically, the method cannot resolve wavenumbers and wave propagation directions if $\mathbf{v}_{a}^{\|}=$ $\mathbf{c}_{p}$, where $\mathbf{v}_{a} \equiv \mathbf{v}_{a}^{\|}+\mathbf{v}_{a}^{\perp}$, and $\mathbf{v}_{a}^{\|}$and $\mathbf{v}_{a}^{\perp}$ are the aircraft 

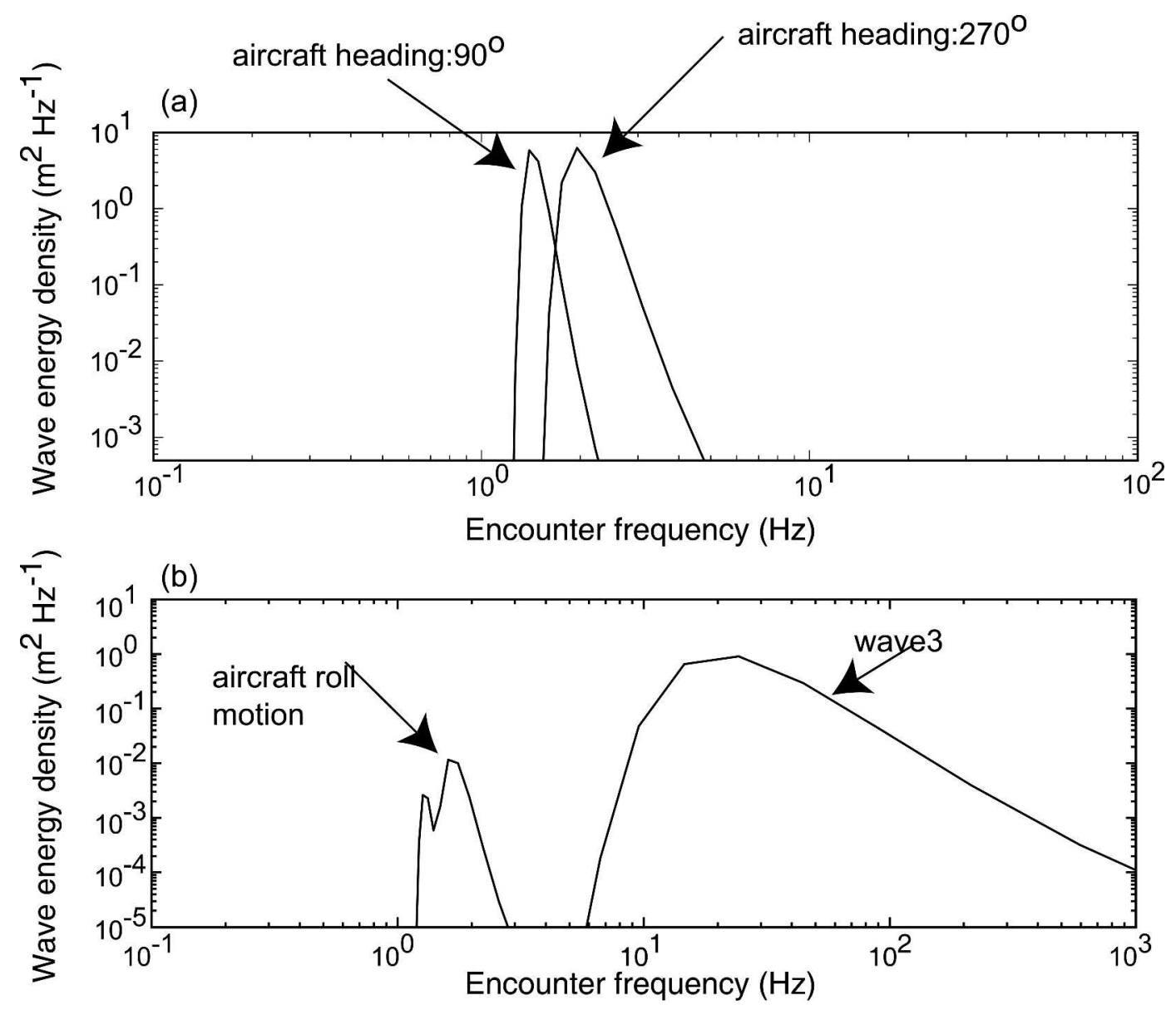

FIG. 3. (a) Wave energy density as a function of the encounter frequency for the single perfect sine wave1 when the aircraft heading is $90^{\circ}$ and $270^{\circ}$. (b) Wave energy density as a function of the encounter frequency for the single sine wave 3 from the aircraft heading of $0^{\circ}$ when the aircraft roll motion is added.

speeds decomposed into the directions parallel to and perpendicular to $\mathbf{c}_{p}$. In this situation, the aircraft travels along wave crests or troughs; therefore, the aircraft cannot measure waves. Notice that this happens when the aircraft heading is not perpendicular to the wave propagation but at an angle from the wave propagation direction. For a single monochromatic wave, the aircraft would "see" the wave as a tower does if the aircraft travels perpendicular to the wave propagation. Since the encounter wave frequency is influenced by the aircraft speed relative to the wave phase speed, the encounter frequency is smaller than the true wave frequency when the aircraft travels in the "same" direction as the wave propagates, that is, $\mathbf{v}_{a} \cdot \mathbf{c}_{p}>0$, and larger when the aircraft travels in the "opposite" direction, that is, $\mathbf{v}_{a} \cdot \mathbf{c}_{p}<0$ (Fig. 3a). Using this fact, the true wave propagation direction in the earth coordinates can be sorted out by comparing the two resolved frequencies at the peak wave energy from two aircraft flights in opposite directions.
Second, the wavelet analysis method is tested when there is random Gaussian noise in surface elevation or in the laser distance measurement. In practice, the noise could be generated from averaging a highsampling-rate laser altimeter data to a lower-samplingrate data, or laser accuracy, or the reflectivity of the sea surface. To simulate this situation, random noise is added to the wave amplitude for all the single waves, which is $5 \%$ of the wave 3 amplitude, that is, $5 \mathrm{~cm}$. Assuming that the random noise is independent between the three lasers, the phase differences between the three laser measurements, or the resolved wavenumber and wave propagation direction, are affected by this uncertainty, as shown in Fig. 2b. When the magnitude of the random noise is as large as the wave amplitude, the wave signal can be completely eliminated; that is, there are no detectable waves. Naturally, the wavelet analysis method would fail if this happened. Since the noise level used in Fig. 2b is relatively small for wave1 and wave2, which have longer wavelengths 

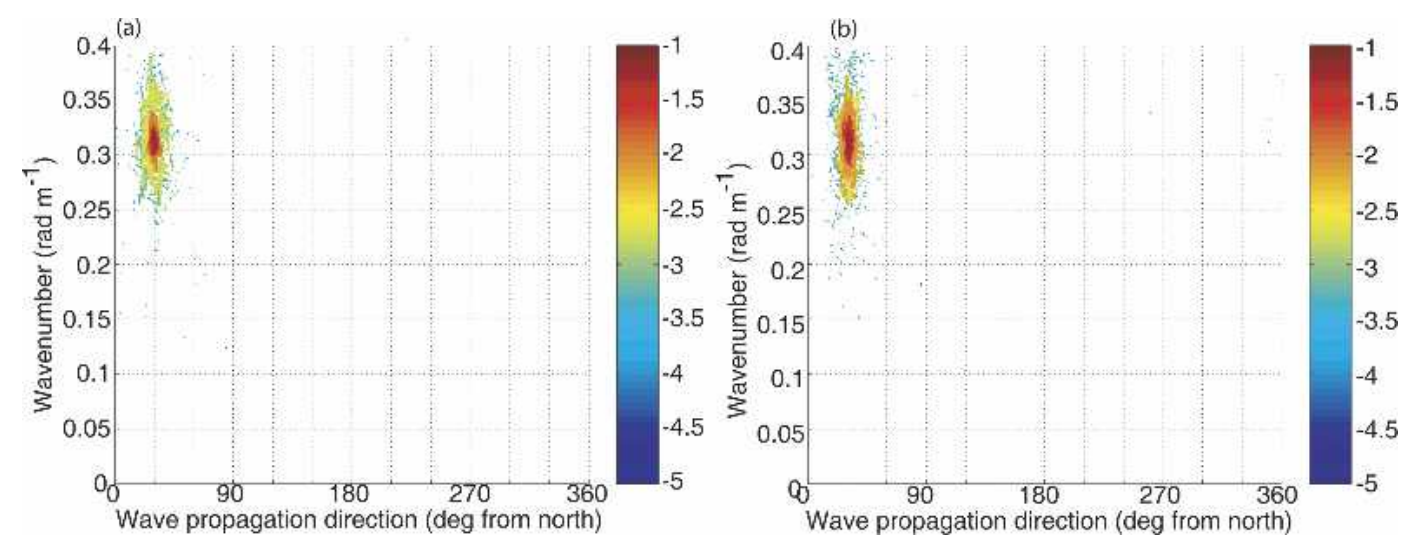

FIG. 4. Wave energy density [the color bar is the log wave energy density $\left(\mathrm{m}^{2} \mathrm{~Hz}^{-1}\right)$ ] as a function of wavenumber and wave propagation direction for wave 3 with the random error at aircraft headings of (a) $90^{\circ}$ and (b) $270^{\circ}$. The different wave energy density from the two aircraft headings is due to the numerical resolution of the wavelet scales (encounter frequency) and the random error.

and larger wave amplitudes, the noise does not affect their resolved wavenumbers and wave directions as much as those for wave3. In addition, the wave energy density as a function of wavenumber and wave propagation direction for the simulated aircraft headings $90^{\circ}$ and $270^{\circ}$ (reverse headings) shows almost-identical single peaks, even though the relatively large random noise is added to wave3 in this case (Fig. 4).

Third, the method is tested if the aircraft rolls or pitches so that the intersection points between the laser beams and the sea surface are not along a straight line as the aircraft flies. When the aircraft rolls, the measured distance from the laser altimeters is longer than the aircraft flight height, and the wave surface measured by the lasers is not directly underneath the aircraft (Fig. 5). To simulate this situation, we assume that the aircraft flies at $15-\mathrm{m}$ height and rolls at a frequency of $1 \mathrm{rad} \mathrm{s}^{-1}$, with a maximum roll angle of $10^{\circ}$, that is, $\theta_{\text {roll }}=10 \sin \left(\omega_{\text {roll }} t\right)$, where $\theta_{\text {roll }}$ is the roll angle, $\omega_{\text {roll }}=$ $1 \mathrm{rad} \mathrm{s}^{-1}$, and $t$ is the time. The roll frequency is chosen to be between the highest and lowest frequency of the idealized waves. Due to the Doppler effect, the encounter wave frequency depends on the aircraft heading. Since the assigned frequency of the aircraft motion is low compared to the wave frequency (Fig. 3b), the encounter frequency of the idealized low-frequency wave 1 is close to the frequency of the aircraft motion when the aircraft heading is around $20^{\circ}-30^{\circ}$ off its propagation direction, $90^{\circ}$. When this happens, the phase difference between the lasers is not only influenced by the waves but also by the aircraft motion. Therefore, the resolved wavenumber and the wave propagation direction do not reflect the true wave state, as shown in Fig. 2c. To resolve the wave information, the aircraft motion has to be removed from the laser measurement, and the measurements of the aircraft roll and pitch motions are required. When the encounter wave frequency is separated from the frequency of the aircraft motion, the resolved wavenumber and wave propagation direction are not affected by the aircraft motion, as explained earlier. Since the frequencies of wave 2 and wave 3 are much higher than the aircraft motion, the encounter frequency of both waves is always separable from the frequency of the aircraft motion, even considering the Doppler effect with various aircraft headings. The influence of the aircraft motion on the wavenumbers and wave propagation directions is not visible in Fig. 2c for the relatively short waves (wave2 and wave3).

For short waves, the wavelet analysis method also depends on the sampling rate of the lasers and the numerical resolution of the wavelet scales (encounter frequency) used in the method. The discrete wavelet scales are evident in Fig. 2 for wave3 due to its rela-

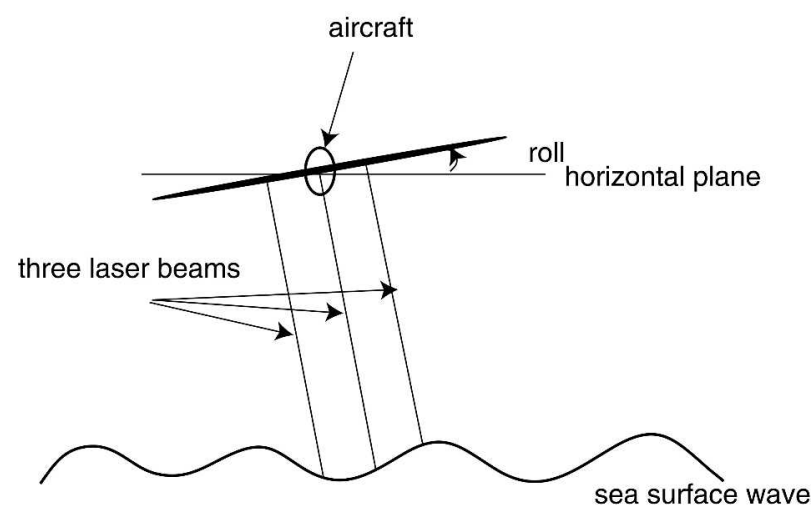

FIG. 5. Schematic of the aircraft roll motion and the three-laser measurement. 
(a) Clean single sine waves
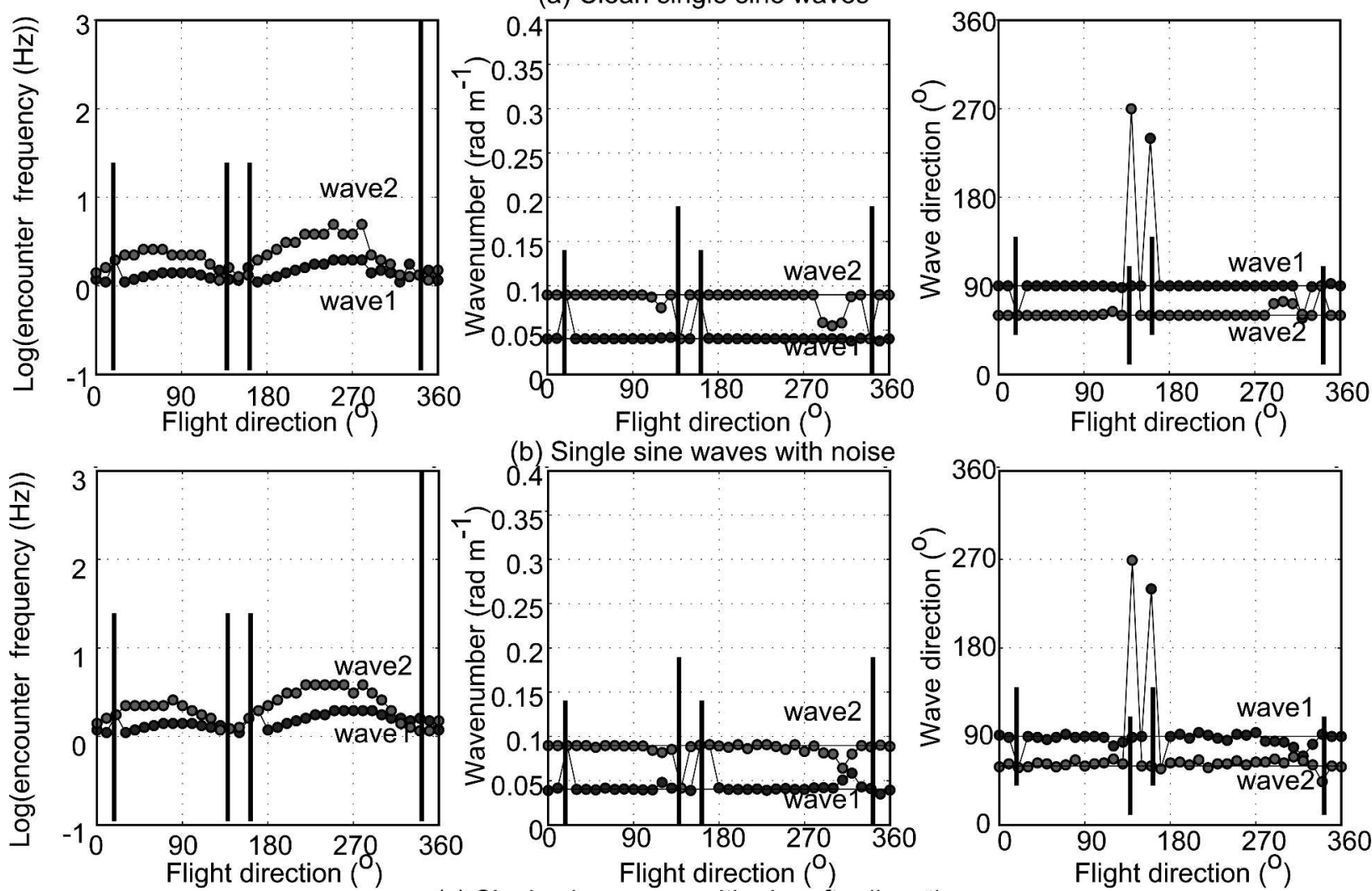

(c) Single sine waves with aircraft roll motion
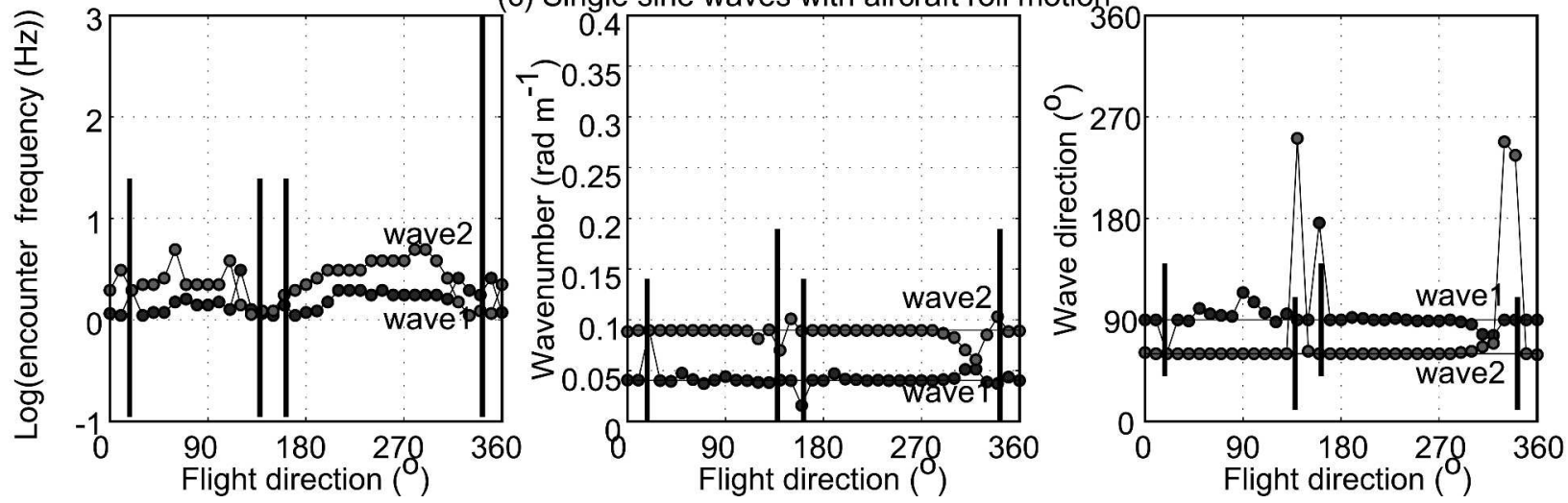

FIG. 6. The same as Fig. 2, except for the wave field that consists of two mixed waves, wave1 and wave2.

tively large variation of the encounter frequency associated with the aircraft heading variation.

Similarly, the aircraft pitch motion or the aircraft altitude variation should not affect the resolved wavenumber and wave propagation direction if these aircraft motions have different frequencies from the wave frequency. Therefore, identifying the encounter wave frequency is important for resolving correct wavenumber and wave direction. Fortunately, the frequency of the aircraft motion varies due to turbulent and mesoscale eddies, while the wave frequency is relatively stable.
The wave frequency can be separated from the frequency of the aircraft motion by analyzing segments of the aircraft data along an aircraft track (section 3).

If the surface wave consists of two perfect monochromatic waves, wave 1 and wave 2 or wave 1 and wave 3 , the wavelet analysis method also successfully resolves the two wavenumbers and their propagation directions (Figs. 6 and 7). As the simulated aircraft heading varies, the encounter frequencies of two waves vary accordingly. Identification of the two encounter wave frequencies is needed. Besides the "bad" aircraft heading 


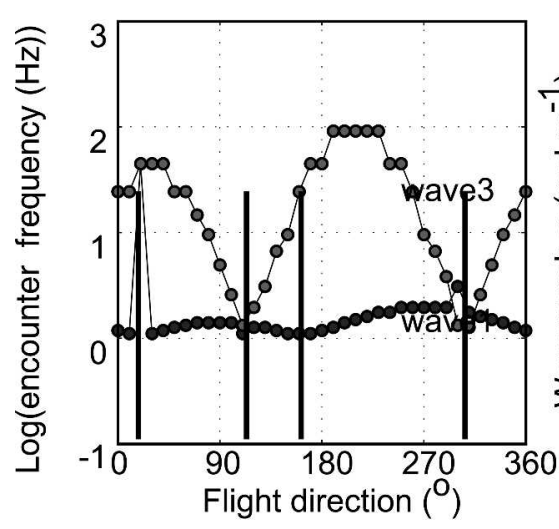

(a) Clean single sine waves
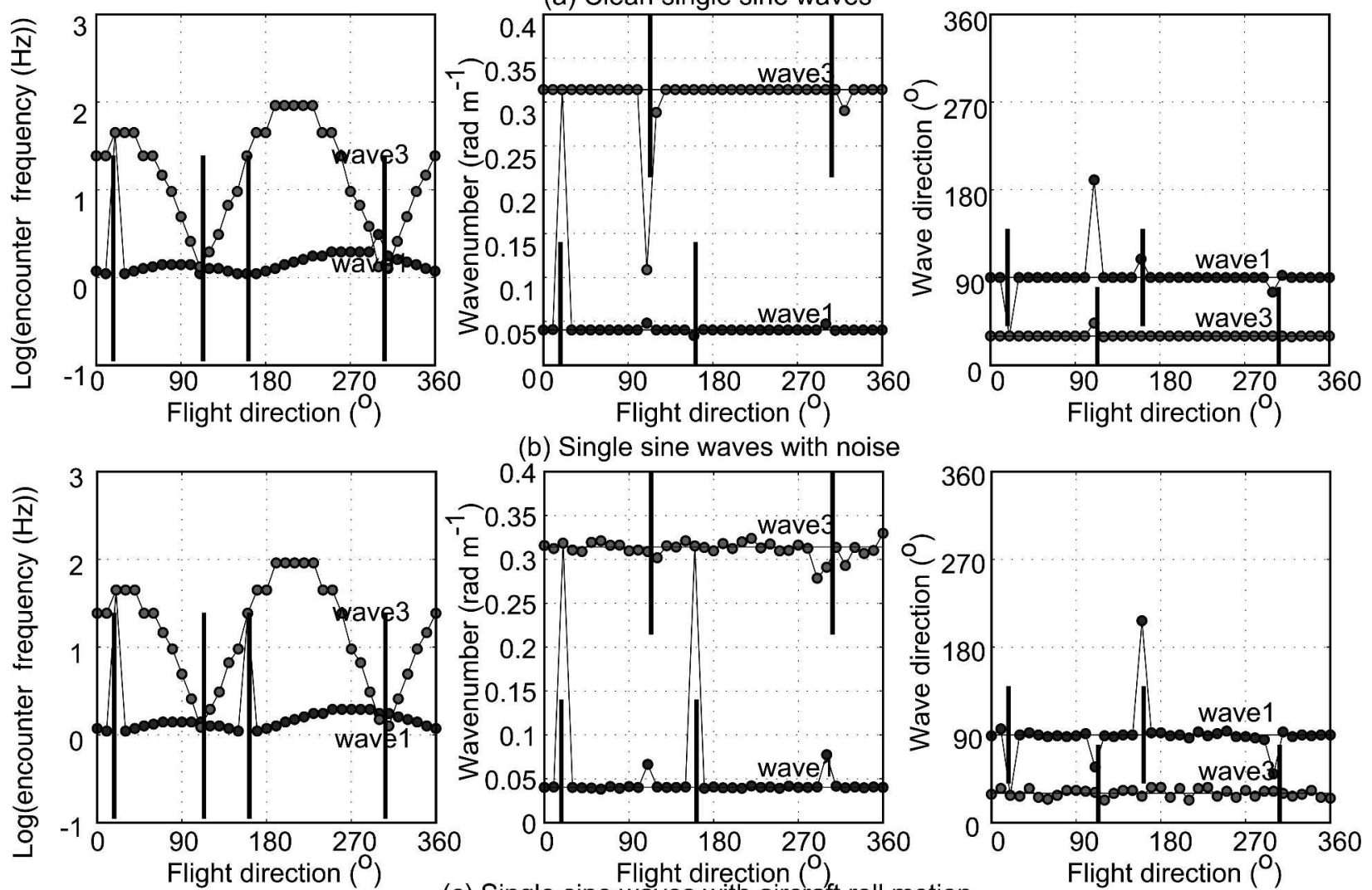

(b) Single sine waves with noise
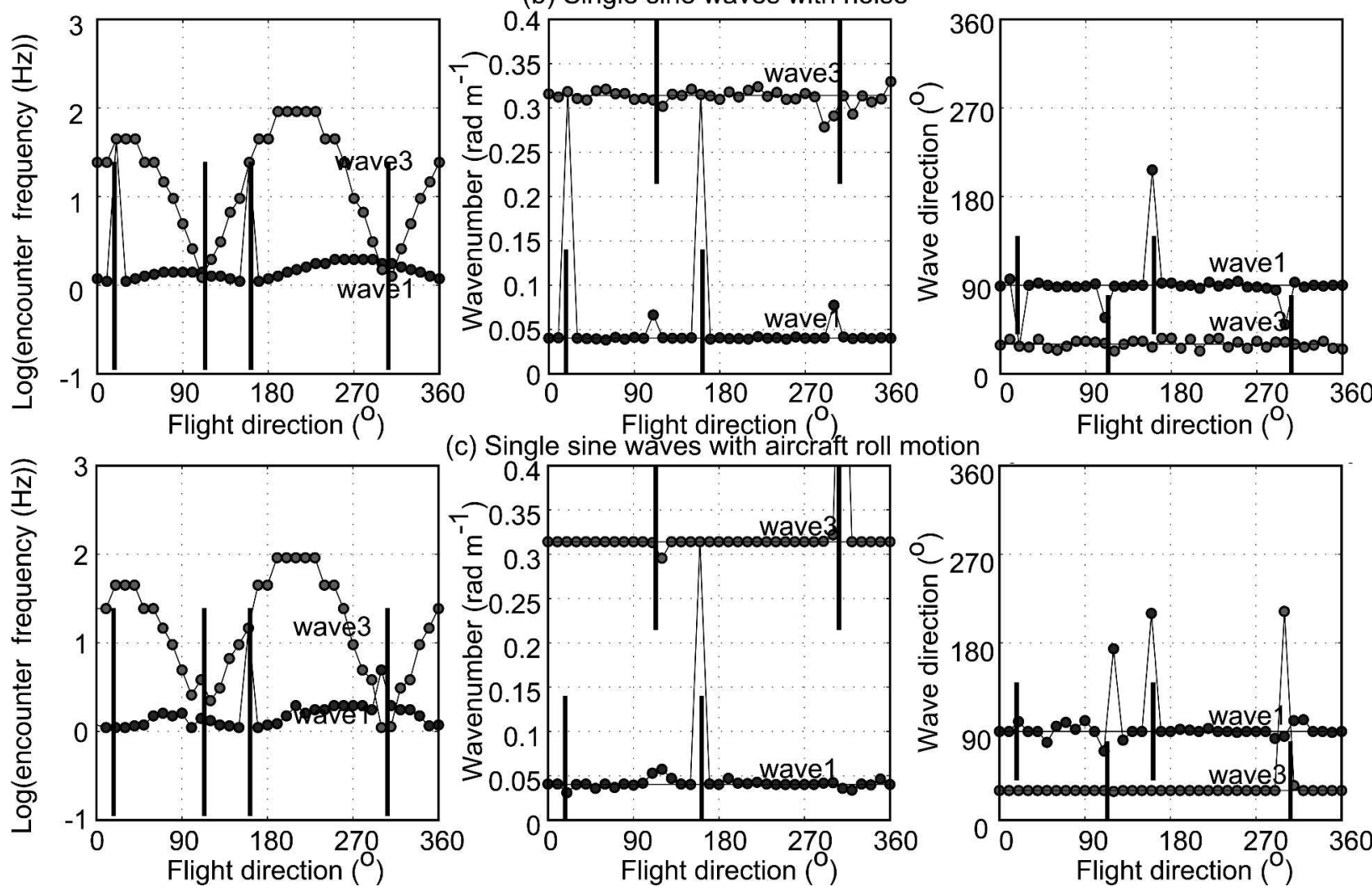

(c) Single sine waves with aircraft roll motion
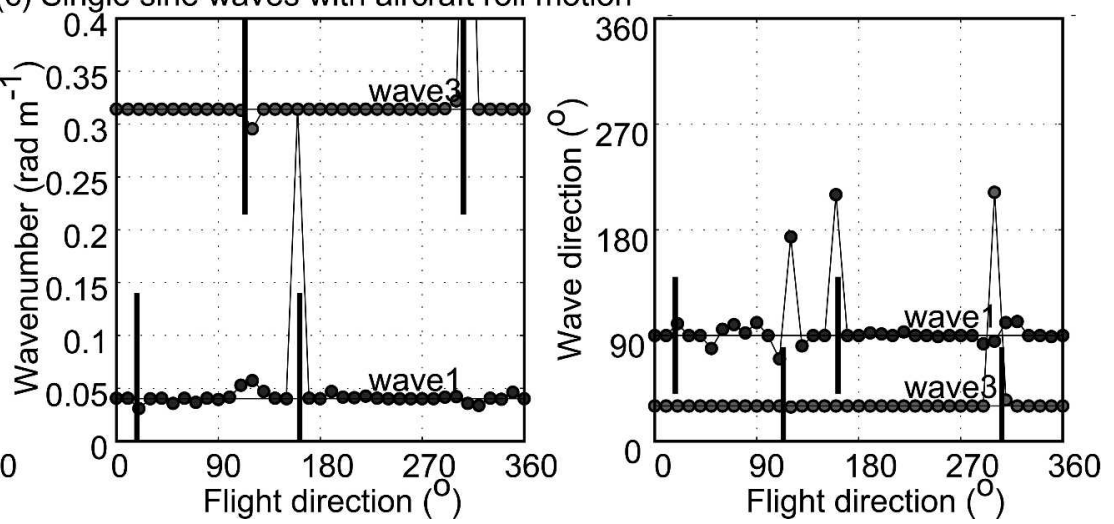

FIG. 7. The same as Fig. 6, except for wave1 and wave3.

mentioned above when the aircraft travels along wave crests or troughs, the wavelet analysis method cannot resolve the wavenumber and wave propagation direction if the aircraft flies in such a direction that two waves with different wavelengths traveling in different directions look the same from the aircraft, that is, the two waves peak at the same encounter frequencies (Fig. 8). Large errors in the resolved wavenumber and wave propagation direction may also occur when the aircraft travels almost along wave crests or troughs, which ap- pear in the wave field consisting of either wave1 and wave 2 or wave 1 and wave 3.

\section{Directional wave spectra from field measurements}

\section{a. Laser instrumentation and data collection}

The laser distance measurements used in this study were taken from the time period when the LongEZ flew approximately along a straight line and at an ap- 


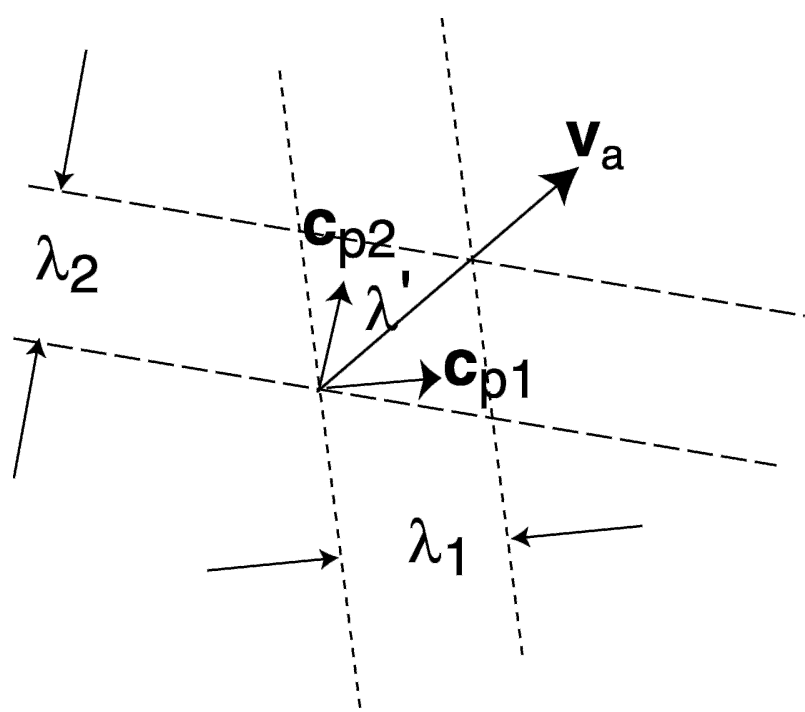

FIG. 8. Schematic of two waves with different wave phase speeds and wavelengths with the same encounter wavelengths observed by the aircraft $\left(\lambda^{\prime}\right)$. The short and long dashed lines represent wave crests for two waves, respectively.

proximately constant height (level run) during SHOWEX (French et al. 2000) off the North Carolina Outer Banks in November-December 1999, and the CBLAST-Low pilot experiment (Crescenti et al. 2001) south of Martha's Vineyard Island, Massachusetts, in July-August 2001. The LongEZ is a small pusher propeller aircraft specially instrumented for researching atmospheric turbulence and surface characteristics (French et al. 2000; Crawford et al. 2001; Crescenti et al. 2002). The LongEZ participated in numerous field experiments, including air-sea and air-land exchange experiments (Crawford et al. 1993; Dobosy et al. 1997; Brooks et al. 1997; Vogel and Crawford 1999; Crescenti et al. 1999; Mourad et al. 2000; Vandemark et al. 2001; Sun et al. 2001). Its ability to measure atmospheric turbulence has been tested in various field experiments in comparison with other flux aircraft (Crawford and Dobosy 1992; Dobosy et al. 1997; Hacker and Crawford 1999; MacPherson et al. 1999).

The LongEZ attitude (pitch, roll, and heading) is determined by combining the low-frequency data (up to $10 \mathrm{~Hz}$ ) collected from a Trimble Advanced Navigation Systems (TANS) differential global positioning system (GPS) with the high-frequency information (up to 50 $\mathrm{Hz}$ ) from accelerometers (Crawford and Dobosy 1997; Eckman et al. 1999). The laser distance measurements from all the level runs during SHOWEX have mean pitch and roll angles of $0.5^{\circ}$ and $-0.5^{\circ}$ (a negative roll indicates that the port wing is lower than the starboard wing), with averaged standard deviations of $0.64^{\circ}$ and $2.95^{\circ}$, respectively. The heading and the elevation of the aircraft may vary during a level run, and their averaged standard deviations for all the level runs during SHOWEX are $4.4^{\circ}$ and $1.8 \mathrm{~m}$, respectively. Similar standard deviations of pitch, roll, heading, and elevation for all the level runs are found during CBLASTLow.

Three laser altimeters (modified Riegl model LD903100 VHS) (Table 2) were aligned with bubble levels so that the laser beams are perpendicular to the average sea surface when the aircraft flies at a constant height (Fig. 9a). The three laser altimeters are mounted on the LongEZ in a triangle with horizontal triangle legs of $0.93,0.93$, and $0.94 \mathrm{~m}$ to simultaneously measure sea surface elevation (Fig. 9b). The forward laser (laser 2, hereafter L2) is mounted along the aircraft centerline of the LongEZ belly instrumentation pod. Laser 1 (L1) and laser 3 (L3) are symmetrically positioned under the port (left side) and starboard (right side) wings, respectively.

The measured laser distance is calculated from the time difference between the emission of an infrared laser pulse from a semiconductor laser diode and the returning of the reflected laser signal to a photodiode receiver. The laser pulses are controlled by an electrical pulse generator at approximately $2000 \mathrm{~Hz}$ for all three lasers during SHOWEX and lasers 1 and 3 during CBLAST-Low. Laser 2 was replaced by a new laser (LD90-3100EHS) during CBLAST-Low, which launches $12 \times 10^{3}$ laser pulses per second. The laser distance measurements were recorded at a rate of 50 $\mathrm{s}^{-1}$ by averaging 38 distinct laser pulse returns during SHOWEX and at a rate of $150 \mathrm{~s}^{-1}$ by averaging 13 laser pulse returns during CBLAST-Low. The number of the laser pulse returns that pass a preset threshold for each recorded laser distance sample was recorded. If all 38 or 13 laser pulses fail to pass the threshold, the reflected laser power strength collected from the photodiode receiver is zero. The three lasers on board the LongEZ were tested by Hall et al. (2000) and Vandemark et al. (2001) in a laboratory. They found that each laser beam intersects the sea surface with a surface area of about

TABLE 2. Riegl laser distance meter (model LD903100VHS-NOAA) characteristics.

\begin{tabular}{|c|c|c|c|}
\hline \multicolumn{2}{|l|}{ Parameter } & \multicolumn{2}{|l|}{ Parameter } \\
\hline Range & $5-60 \mathrm{~m}$ & $\begin{array}{l}\text { Laser footprint } \\
\quad \text { (at } 12.5 \mathrm{~m})\end{array}$ & $0.035 \times 0.06 \mathrm{~m}$ \\
\hline Accuracy & $\pm 0.02 \mathrm{~m}$ & Laser wavelength & $0.9035 \mu \mathrm{m}$ \\
\hline Resolution & $0.02 \mathrm{~m}$ & Beam divergence & $3 \times 0.5 \mathrm{mrad}^{*}$ \\
\hline Pulse rate & $2000 \mathrm{~Hz}$ & Nominal accuracy & $\pm 2 \mathrm{~mm}$ \\
\hline
\end{tabular}

* $1 \mathrm{mrad}$ corresponds to $10 \mathrm{~cm}$ increasing beamwidth per $100 \mathrm{~m}$ of distance. 
(a) Sideview of NOAA LongEZ

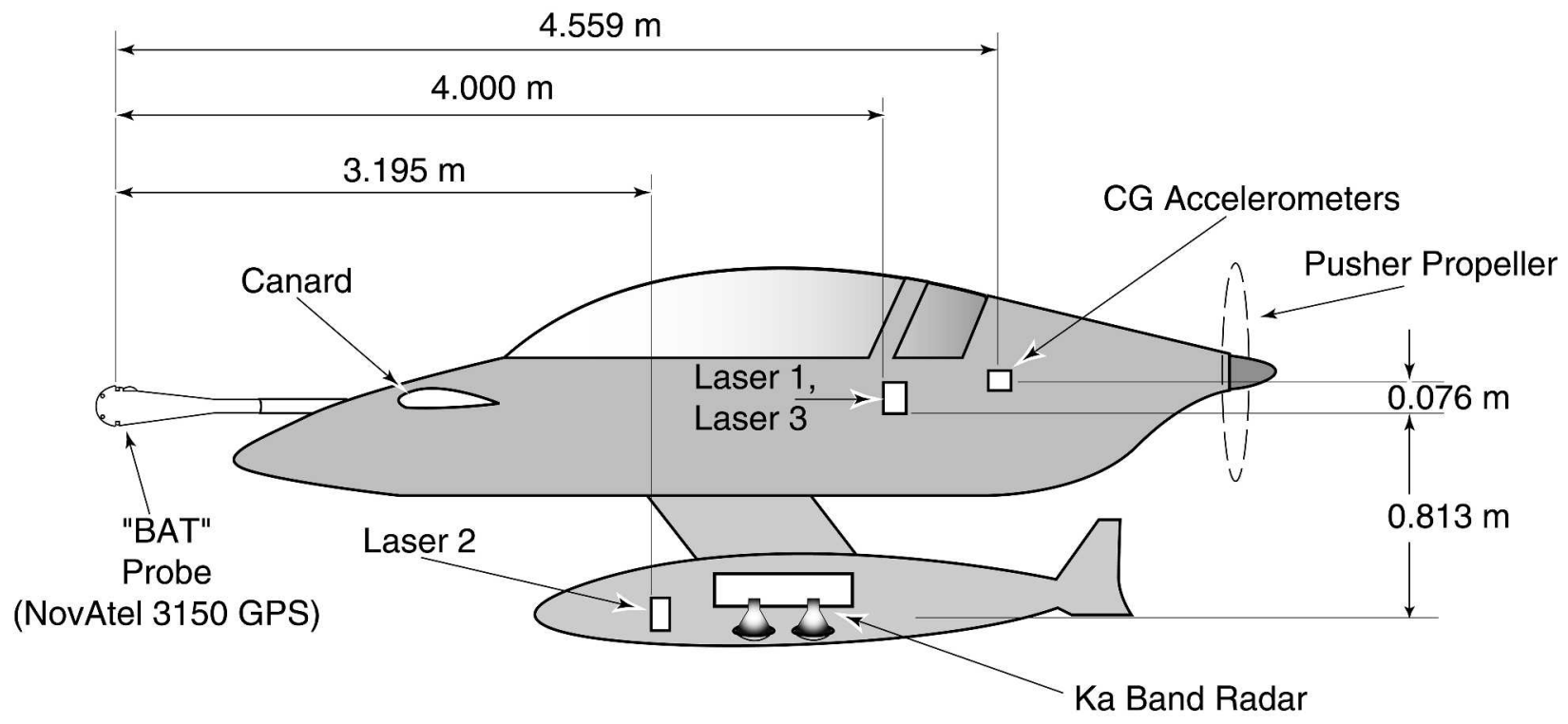

(b) Plan view of three laser altimeters

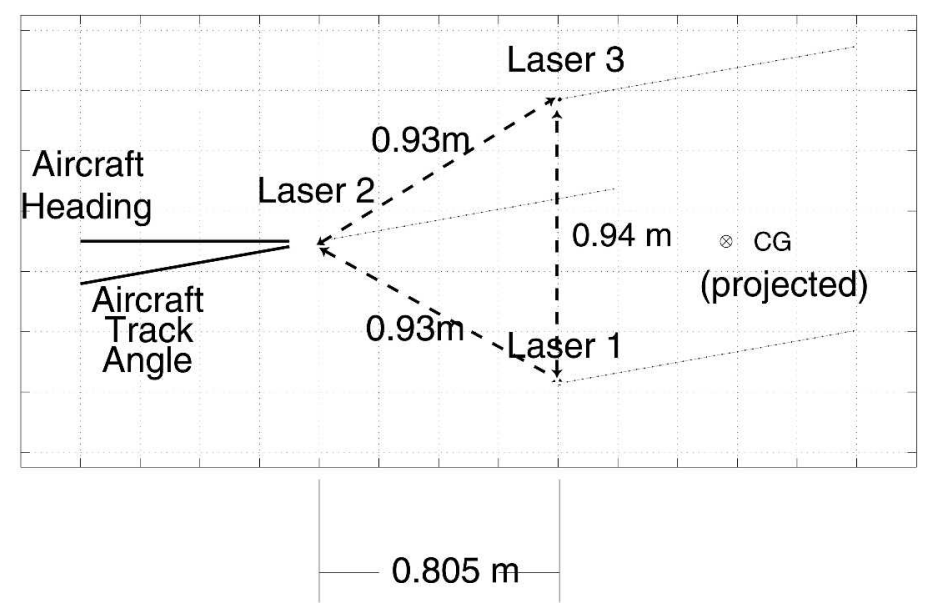

FIG. 9. The (a) side view and (b) plan view of the LongEZ aircraft laser-related instrumentation. Here the aircraft heading and flight track are $270^{\circ}$ and $260^{\circ}$ from the north, respectively. Thin lines of about $1 \mathrm{~m}$ behind each laser represent the distance over which the 38 laser pulses are averaged for a single laser distance sample during SHOWEX. The belly pod in (a) is exaggerated so the location of laser 2 can be clearly shown.

$0.035 \mathrm{~m}$ (along-flight track) $\times 0.06 \mathrm{~m}$ (cross-flight track) when the aircraft flies at a height of $12.5 \mathrm{~m}$. They also found that the probability of obtaining a laser return over a smooth surface is small since it depends on the chance of having a surface within the small footprint of the laser beam to be oriented perpendicular to the laser beam. When the laser beam fails to reflect directly back to the laser receiver, the laser distance is zero and a data dropout appears in the laser data series.
The number of the laser pulse returns that pass the threshold for each laser distance sample is higher under strong wind than weak wind conditions during SHOWEX (Fig. 10), since strong winds are associated with a rough sea surface, and the chance for reflected laser beams to reach the receiver is higher. Similar number distributions of the laser pulse return were also found from the laboratory test by Hall et al. (2000).

By averaging over the number of pulse returns, ran- 
(a)

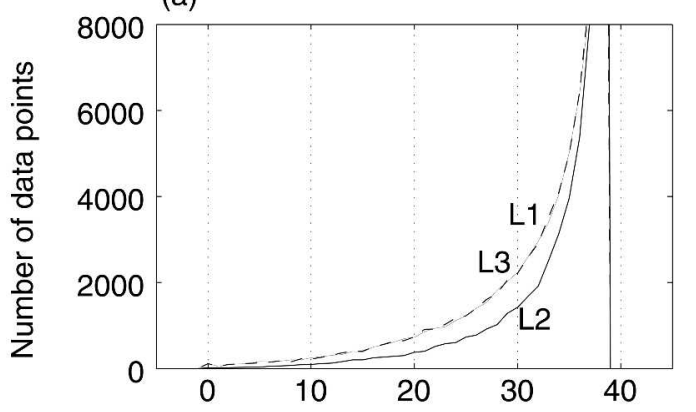

No. of returns for each data sample (counts)

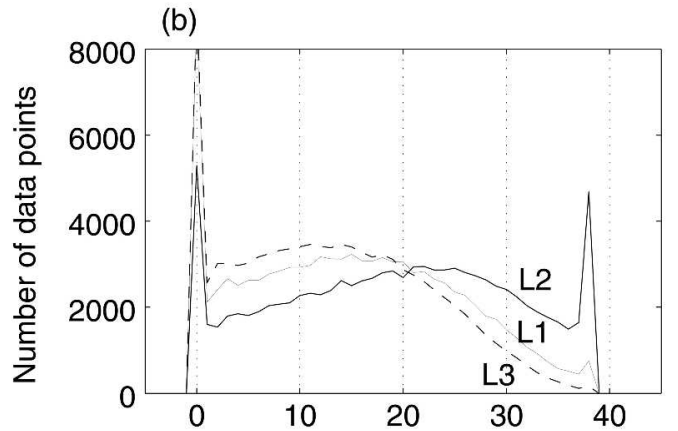

No. of returns for each data sample (counts)

FIG. 10. Laser sample distribution as a function of the number of laser pulse returns that pass the preset threshold for each recorded laser distance sample for (a) a run on 15 Nov 1999 when the wind speed was $9.7 \mathrm{~m} \mathrm{~s}^{-1}$ and (b) a run on 20 Nov 1999 when the wind speed was $3.2 \mathrm{~m} \mathrm{~s}^{-1}$.

dom measurement errors are reduced. However, small spatial variations of surface waves are smeared out. For the aircraft flying at a ground speed of between 40 and $65 \mathrm{~m} \mathrm{~s}^{-1}$, the surface elevation measurement is averaged over a distance of $\sim 1 \mathrm{~m}$ during SHOWEX (Fig. $9 b$ ) and $\sim 0.33 \mathrm{~m}$ during CBLAST-Low. Because of the size of the laser triangle, the smallest wave measured by the three lasers has a wavelength of $\sim 2 \mathrm{~m}$. In this study, the laser distance data from CBLAST-Low are downsampled at the rate of $50 \mathrm{~s}^{-1}$ to match the sampling rate of the aircraft heading. However, each laser sample in CBLAST-Low is averaged over a third of the aircraft traveling distance from SHOWEX. With the preset focal distance of $15 \mathrm{~m}$, the laser altimeters can measure distances ranging from about 5 to $50 \mathrm{~m}$, although the percentage of the laser dropouts increases when the aircraft flies higher than $15 \mathrm{~m}$.

\section{b. Laser data processing}

To calculate 2D surface wave spectra, we removed data spikes due to data dropouts from an insufficient number of pulse returns, which may occur over smooth surfaces or target distances out of the focus range. To identify these data spikes, a four-pole Butterworth zero-phase-shift low-pass filter with a cutoff frequency of $10 \mathrm{~Hz}$ is applied iteratively to the three laser distance measurements. As the difference between the filtered $\left(D_{\text {laser }}^{f}\right)$ and raw $\left(D_{\text {laser }}\right)$ laser distances exceeds a preset threshold $D_{\text {limit }}=0.004 \mathrm{~m}$, the raw data are detected as spikes. The threshold was determined based on numerous test runs from SHOWEX. The spikes are replaced with spline-fit data using valid measurements at adjacent times.

Based on Hall et al.'s laboratory test, the lasers may drift with time, and the laser drifts are independent of each other. The major laser drift is due to the laser warm-up period when the laser altimeters are turned on before each flight. Nonetheless, the absolute accuracy of the laser distance measurement remains $\pm 2 \mathrm{~cm}$. The mean distance differences measured between the three laser altimeters are removed.

\section{c. Directional wave spectra during CBLAST-Low and SHOWEX}

On 25 July 2001, a north-south-orientated track of about $48 \mathrm{~km}$ was flown at about 12-m height during CBLAST-Low (Fig. 11a). The entire track is divided into six $8-\mathrm{km}$ segments to investigate spatial variations of wave spectra. We found that the low-frequency motion varies between segments, but the location of the encounter wave spectral peak is relatively steady (Fig. 12). Independent spectra analysis of the aircraft altitude, roll, and pitch motions confirmed that the variable low-frequency motion in Fig. 12 was indeed from the aircraft motion. The wavelet analysis indicates that the most wave energy was from the wave direction around $200^{\circ}$ with a wavenumber of about $0.1 \mathrm{rad} \mathrm{m}^{-1}$ (Fig. 13). This wave information agrees well with the buoy observation at Martha's Vineyard Coastal Observatory (MVCO), where the peak wave period of $8 \mathrm{~s}$ and the peak wave propagation of $200^{\circ}$ were found at the time of the flight. Comparison between the wave information from the segment close to the coast (segment 1) and the segment away from the shore (segment 5) shows that the wavelength increased slightly with offshore distance, and the wave propagation direction spread around $200^{\circ}$ from the coast to the open ocean.

The wave energy density as a function of wavenumber and wave direction is derived by averaging the wave energy of all the resolved wavelet scales and time, which have the same wavenumber and wave direction. Since the resolved waves do not have energy at every 
(a) CBLAST

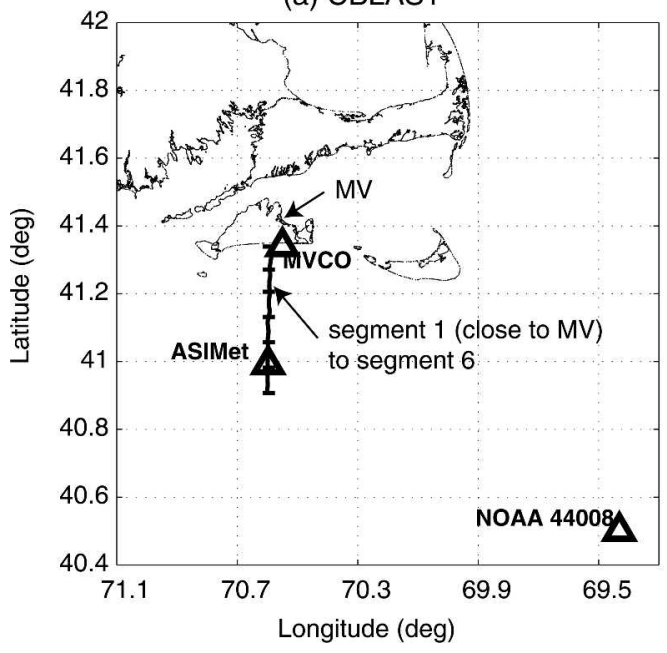

(b) SHOWEX

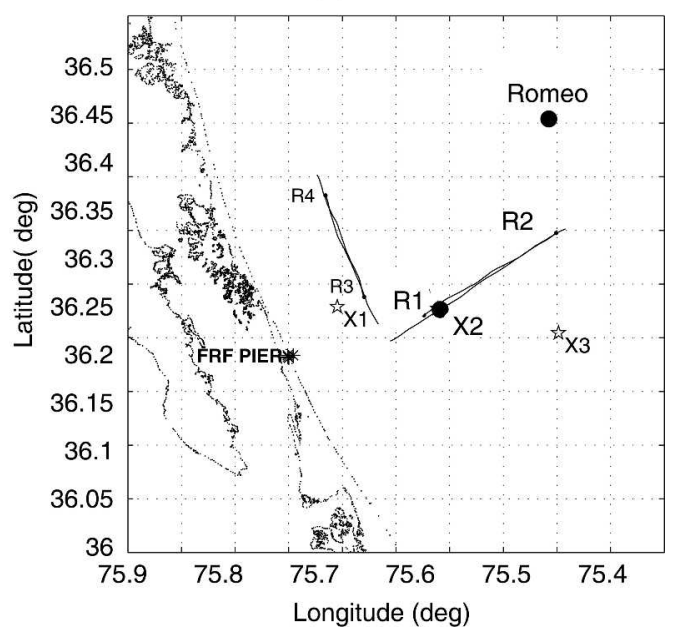

FIG. 11. (a) The flight segments on 25 Jul 2001 off the coast of Martha's Vineyard (MV), MA, during CBLASTLow and (b) the flight tracks, R1 (the aircraft flew toward NE), R2 (toward SW), R3, and R4 on 15 Nov 1999, offshore of NC. X1, X2, and X3 in (b) are the Datawell Directional Waveriders. Romeo is an ASIS (air-sea interaction spar) buoy.

pair of wavenumber and wave direction in Fig. 13, the figure looks discrete. Theoretically, the aircraft would miss the wave that has the zero encounter frequency [Eq. (11)]. Since the aircraft velocity fluctuates according to the ambient flow, the "missed" wave frequency varies with time. Because Fig. 13 is averaged over all the available data points, the wave energy density at the wavenumbers and wave propagation directions that correspond to the "missed" wave frequency at a time is not affected.

On 15 November 1999, the LongEZ aircraft flew over a number of buoys at a $20-\mathrm{m}$ height during SHOWEX (Fig. 11b). The wavelet analysis was performed using the data along flight tracks R1 and R2, which were two reverse-heading level runs of $15 \mathrm{~km}$. The encounter frequencies at the peak waves from two reverse-heading runs show that the encounter frequency from R1 is higher than that from R2, indicating that the wave propagated in the opposite direction to the aircraft heading during the R1 run, that is, that the wave came from the northeast (Fig. 14). The wavelet analysis shows that the most wave energy is from between $350^{\circ}$ and $20^{\circ}$ (Figs. 15a,b), which agrees well with the wave spectra obtained from the Datawell Directional Waverider at X2 using the maximum entropy method (Lygre and Krogstad 1986) (Fig. 15c). Although the wave energy density from the waverider data and from the laser altimeter data has different units, both methods capture the similar patterns of the wave energy density as a function of wavenumbers and wave directions.

\section{Concluding remarks}

A three-laser nadir-looking system on board the LongEZ aircraft for measurements of characteristics of the ocean surface is described. A wavelet analysis method from Donelan et al. (1996) is used to resolve directional wave spectra. The crucial feature for the success of the wavelet analysis method is that the wavenumber and the wave propagation direction are not derived from the encounter frequency (wavelet scales) distribution of the laser measurement but the phase difference associated with the wave slope from the si-

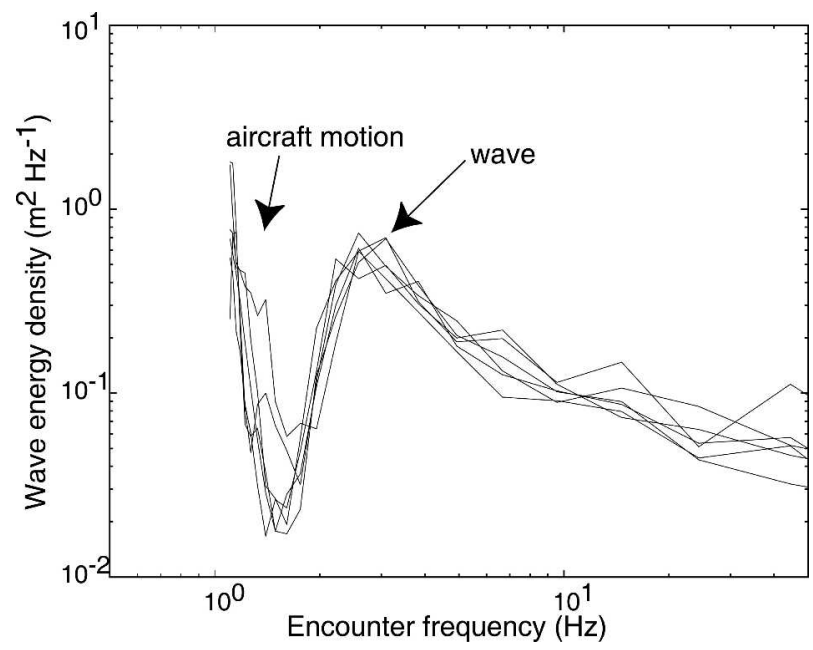

FIG. 12. Wave energy density vs encounter wave frequency distribution for the six 8-km segments from the outgoing flight on 25 Jul 2001 during CBLAST-Low. 

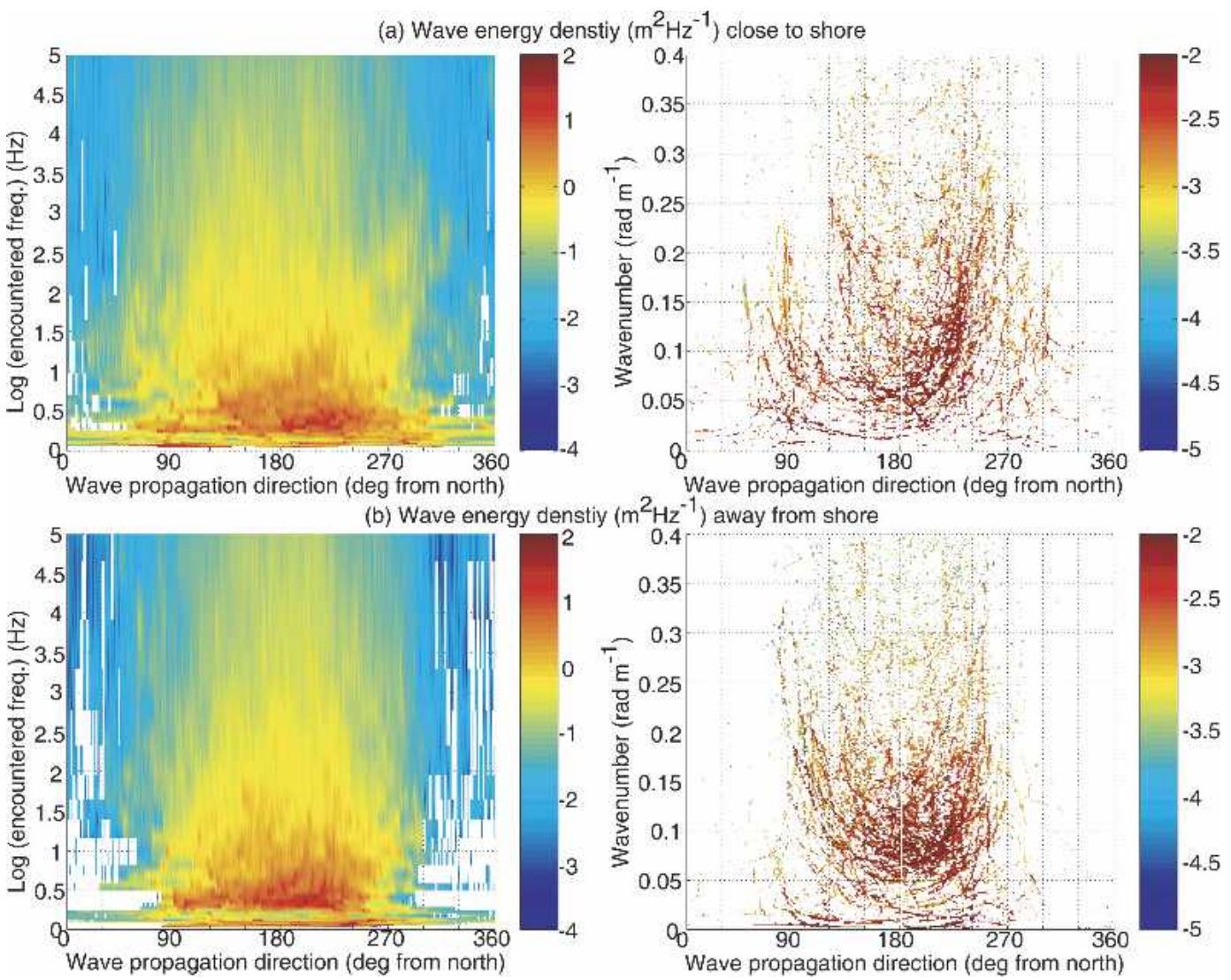

FIG. 13. Wave energy density as a function of the encounter frequency and wave propagation direction, and as a function of the wavenumber and wave propagation direction for (a) close to the shore (segment 1) and (b) away from the shore (segment 5) on 25 Jul 2001 during CBLAST-Low. Here the contribution of the aircraft lowfrequency motion in the wavenumber-wave direction plots is removed.

multaneous three-laser measurements. Because the distance measurement is decomposed into various encounter frequencies, the true wavenumber and the wave propagation direction at the encounter wave frequency can be resolved without any influence of the aircraft motion, including roll and pitch motions, varying aircraft heading, and altitude, on the laser distance measurement, if the frequencies of the wave and the aircraft motion are separable. The aircraft heading information is needed for obtaining the wave propagation direction relative to the north. The Doppler effect associated with the aircraft speed relative to the wave propagation only affects the encounter frequency but not the resolved wavenumber and wave direction. Here the encounter frequency is not the true frequency of wave motion as observed at a fixed location but is altered by the Doppler shift and varying flight tracks (not along a straight line). By taking the advantage of the Doppler effect, the wave propagation direction can be sorted out from flights with reverse flight headings.

When the frequency of the aircraft motion is close to the wave frequency, the laser distance measurement associated with the aircraft motion has to be removed in order to obtain the true wavenumber and wave propagation direction. Based on the aircraft data col-

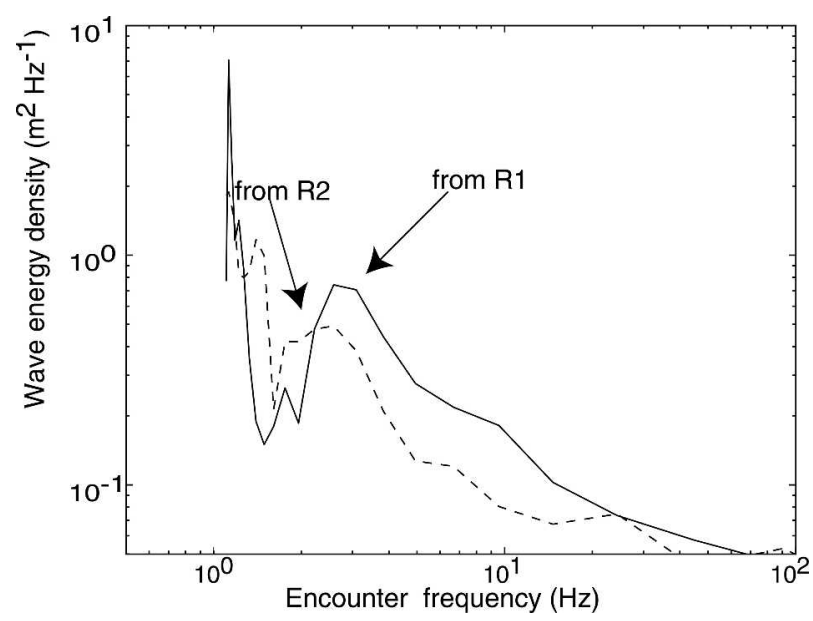

FIG. 14. Wave spectra from the R1 (solid) and R2 (dashed) runs on 15 Nov 1999 during SHOWEX. 

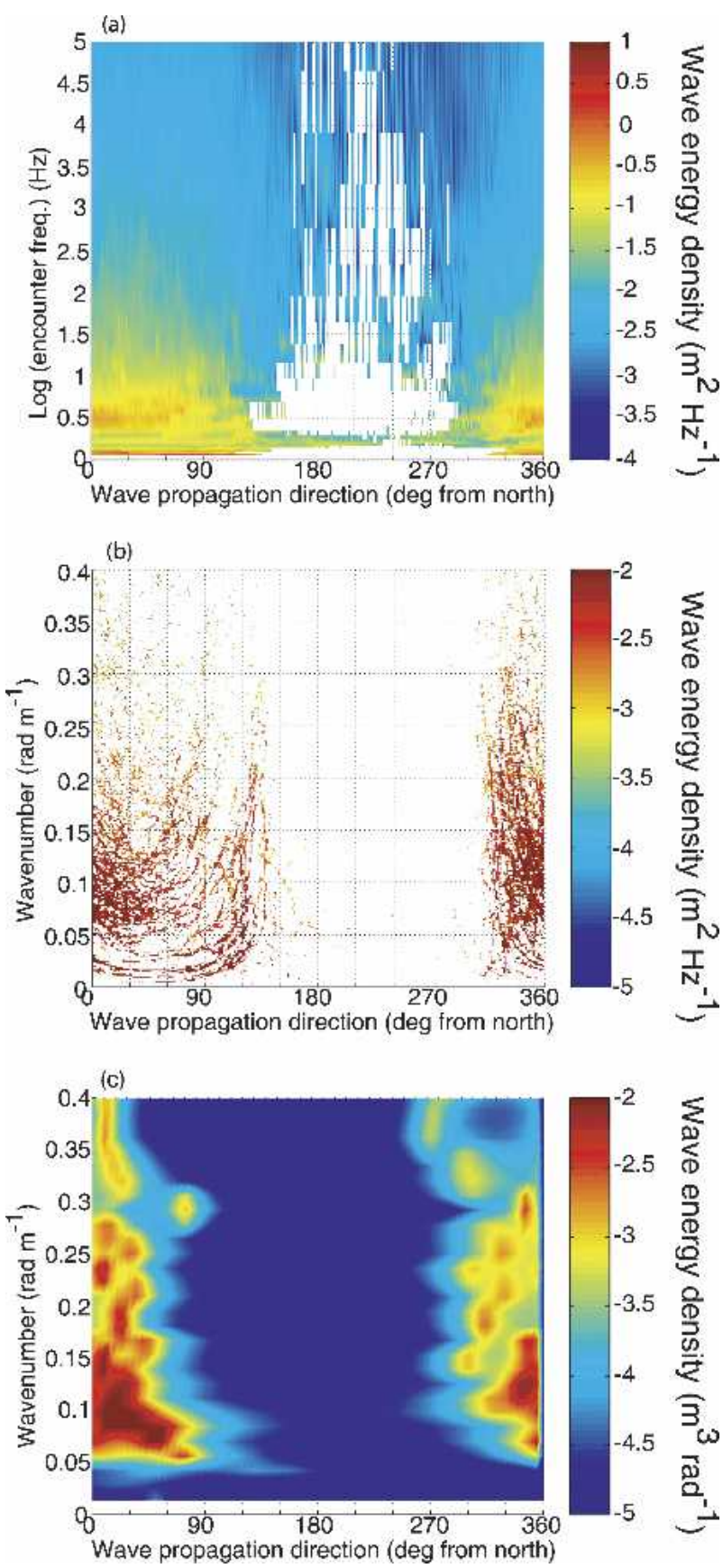

FIG. 15. Wave energy density (a) as a function of encounter frequency and wave propagation direction from the north, (b) as a function of wavenumber and wave propagation direction from the north from R1, and (c) from the Datawell Directional Waverider at X2 on 15 Nov 1999 during SHOWEX.

lected from SHOWEX and CBLAST-Low, the aircraft motion tends to have lower frequencies, and varies due to the influence of ambient flow conditions, while the wave frequency tends to be more steady during aircraft flights.
The sensitivity of the wavelet analysis method to aircraft heading relative to wave propagation direction, aircraft motion, and data noise for various wave amplitudes and wavelengths was tested using idealized wave fields. We found that the method can successfully resolve wavenumber and wave propagation direction for all the tests except under the following conditions: 1) when the aircraft travels in such a direction that the aircraft travel speed along the wave propagation direction is the same as the wave propagation speed, that is, the aircraft travels along wave crests or troughs; and 2) when the aircraft travels in such a direction that two waves with different wavelengths and wave propagation directions and speeds have the same encounter frequency as observed from the aircraft. The horizontal distance between the laser altimeters determines the size of wave slope that the three laser altimeters can measure, which in turn determines the minimum wavelength of the surface wave that the aircraft can measure. Large errors or uncertainties may also result from instrument errors that are independent of each other. In our tests, the data noise was assumed to be $5 \mathrm{~cm}$ in the surface elevation, which is larger than the maximum uncertainty of the laser measurement, $\pm 2 \mathrm{~cm}$, from the laboratory tests. Two cases from field experiments, one from SHOWEX and one from CBLAST-Low, were also used to test the wavelet analysis method. The resolved wavenumber and wave propagation compared well with buoy observations at the site.

Based on our investigation, we recommend that the aircraft flies along a track with reverse headings, and two separate tracks should be considered to ensure the success of the wavelet analysis method by avoiding the same travel speed between the wave and the aircraft along the wave propagation direction. In addition, the wavelet analysis method can also be used on other moving platforms. In a subsequent study, we will investigate spatial variations of directional wave spectra and their correlation with spatial variations of atmospheric turbulence.

Acknowledgments. Dr. Timothy Crawford was one of the most important members in our SHOWEX and CBLAST-Low teams. He not only contributed to the scientific plan but also flew the LongEZ himself. His enthusiasm on the projects and hard work made both projects possible. He collapsed and died during a CBLAST-Low solo flight. He is sorely missed by his colleagues, especially our team. We dedicate this paper to his memory.

Jielun Sun and Sean Burns were supported by ONR Grant N00014-98-1-0245 for SHOWEX and by ONR Grant N00014-01-C-0108 for CBLAST-Low. Mark 
Donelan was supported by ONR Grant N00014-97-10348. Larry Mahrt was supported by ONR Grant N000140110084. The NOAA LongEZ aircraft group was supported by ONR Contract N00014-97-F-0123 for the SHOWEX field experiment and by ONR Contract N00014-01-F-0008 for CBLAST-Low. Thomas Herbers was supported by ONR Grant N0001404WR20065. We would also like to thank two anonymous reviews for their valuable comments.

\section{REFERENCES}

Banner, M. L., W. Chen, E. J. Walsh, J. B. Jensen, S. Lee, and C. Fandry, 1999: The Southern Ocean Waves Experiment. Part I: Overview and mean results. J. Phys. Oceanogr., 29, 21302145.

Beal, R. C., T. W. Gerling, D. E. Irvine, F. M. Monaldo, and D. G. Tilley, 1986: Spatial variations of ocean wave directional spectra for the SEASAT synthetic aperture radar. J. Geophys. Res., 91, 2433-2449.

Brooks, S. B., T. L. Crawford, and W. C. Oechel, 1997: Measurements of carbon dioxide emissions plumes from Prudhoe Bay, Alaska oil fields. J. Atmos. Chem., 27, 197-207.

Capon, J., 1969: High-resolution frequency-wavenumber spectrum analysis. Proc. IEEE, 57, 1408-1419.

Chen, W., M. L. Banner, E. J. Walsh, J. B. Jensen, and S. Lee, 2001: The Southern Ocean Waves Experiment. Part II: Seasurface response to wind speed and wind stress variations. $J$. Phys. Oceanogr., 31, 174-198.

Cox, C., and W. Munk, 1954: Statistics of the sea surface derived from sun glitter. J. Mar. Res., 13, 198-227.

Crawford, T. L., and R. J. Dobosy, 1992: A sensitive fast-response probe to measure turbulence and heat flux from any airplane. Bound.-Layer Meteor., 59, 257-278.

— climate. GPS World, 8, 32-39.

$\longrightarrow$, R. T. McMillen, T. P. Meyers, and B. B. Hicks, 1993: Spatial and temporal variability of heat, water vapor, carbon dioxide, and momentum air-sea exchange in a coastal environment. $J$. Geophys. Res., 98, 12 869-12 880.

— , G. H. Crescenti, and J. M. Hacker, 2001: Small environmental research aircraft: The future of airborne geoscience. Preprints, 11th Symp. on Meteorological Observations and Instrumentation, Albuquerque, NM, Amer. Meteor. Soc., 117122.

Crescenti, G. H., T. L. Crawford, and E. J. Dumas, 1999: Data report: LongEZ (N3R) participation in the 1999 Shoaling Waves Experiment (SHOWEX) pilot study. NOAA Tech. Memo. ERL ARL-232, Silver Spring, MD, 86 pp.

— J. R. French, and T. L. Crawford, 2001: Aircraft measurements in the Coupled Boundary Layers Air-Sea Transfer (CBLAST) light wind pilot field study. NOAA Tech. Memo. OAR ARL-241, Silver Spring, MD, 82 pp.

$\longrightarrow,-,-$, and D. C. Vandemark, 2002: An integrated airborne measurement system for the determination of atmospheric turbulence and ocean surface wave field properties. Preprints, Sixth Symp. on Integrated Observing Systems, Orlando, FL, Amer. Meteor. Soc., 60-67.

Davis, R. E., and L. A. Regier, 1977: Methods for estimating directional wave spectra from multielement arrays. J. Mar. Res., 35, 453-477.

Dobosy, R. J., T. L. Crawford, J. I. MacPherson, R. L. Desjardins,
R. D. Kelly, S. P. Oncley, and D. H. Lenschow, 1997: Intercomparison among four flux aircraft at BOREAS in 1994. $J$. Geophys. Res., 102, 29 101-29 111.

Donelan, M. A., W. M. Drennan, and A. K. Magnusson, 1996: Nonstationary analysis of the directional properties of propagating waves. J. Phys. Oceanogr., 26, 1901-1914.

Eckman, R. M., T. L. Crawford, E. J. Dumas, and K. R. Birdwell, 1999: Airborne meteorological measurements collected during the Model Validation Program (MVP) field experiments at Cape Canaveral, Florida. NOAA Tech. Memo. OAR ATDD-233, Silver Spring, MD, 54 pp.

Farge, M., 1992: Wavelet transforms and their applications to turbulence. Annu. Rev. Fluid Mech., 24, 395-457.

Frasier, S. J., Y. Liu, D. Moller, R. E. McIntosh, and C. Long, 1995: Directional ocean wave measurements in a coastal setting using a focused array imaging radar. IEEE Trans. Geosci. Remote Sens., 33, 428-440.

French, J. R., G. H. Crescenti, T. L. Crawford, and E. J. Dumas, 2000: LongEZ (N3R) participation in the 1999 Shoaling Waves Experiment (SHOWEX). NOAA Data Rep. OAR ARL-20, Silver Spring, MD, 51 pp.

Hacker, J. M., and T. L. Crawford, 1999: The BAT-probe: The ultimate tool to measure turbulence from any kind of aircraft (or sailplane). Tech. Soaring XXIII, 2, 43-46.

Hall, E., D. Vandemark, S. Long, and N. Tran, 2000: Laboratory tests of Riegl infrared laser distance sensors: Range stability and water reflection characteristics. National Space Club Scholar Summer Intern Project, July 2000, NASA Goddard Space Flight Center, Wallops Flight Facility, Wallops Island, VA, 35 pp. [Available online at http://rows.wff.nasa.gov/ riegl_tests.wff2000.pdf.]

Hasselmann, D. E., M. Dunckel, and J. A. Ewing, 1980: Directional wave spectra observed during JONSWAP 1973. J. Phys. Oceanogr., 10, 1264-1280.

Herbers, T. H. C., and R. T. Guza, 1990: Estimation of directional wave spectra from multicomponent observations. J. Phys. Oceanogr., 20, 1703-1724.

Howell, J. F., and L. Mahrt, 1997: Multiresolution flux decomposition. Bound.-Layer Meteor., 83, 117-137.

Huang, N. E., Y. Toba, Z. Shen, J. Klinke, B. Jahne, and M. L. Banner, 2001: Ocean wave spectra and integral properties. Wind Stress over the Ocean, I. S. Jones and Y. Toba, Eds., Cambridge University Press, 82-123.

Hwang, P. A., 1995: Spatial measurements of small-scale ocean waves. Air-Water Gas Transfer: Selected Papers from the Third International Symposium on Air-Water Gas Transfer, B. Jahne and E. C. Monahan, Eds., AEON Verlag \& Studio, 153-164.

- W. B. Krabill, W. Wright, R. N. Swift, and E. J. Walsh, 2000a: Airborne scanning lidar measurement of ocean waves. J. Remote Sens. Environ., 73, 236-246.

- D. W. Wang, E. J. Walsh, W. B. Krabill, and R. N. Swift, 2000b: Airborne measurements of the wavenumber spectra of ocean surface waves. Part I: Spectral slope and dimensionless spectral coefficient. J. Phys. Oceanogr., 30, 2753-2767.

$-,-, \ldots,-$, and,$- 2000 \mathrm{c}$ : Airborne measurements of the wavenumber spectra of ocean surface waves. Part II: Directional distribution. J. Phys. Oceanogr., 30, 2768-2787.

Kitaigordskii, S. A., V. P. Krasitskii, and M. M. Zaslavskii, 1975: On Phillips' theory of equilibrium range in the spectra of wind-generated gravity waves. J. Phys. Oceanogr., 5, 410-420.

Krogstad, H. E., R. L. Gordon, and M. C. Miller, 1988: Highresolution directional wave spectra from horizontally 
mounted acoustic Doppler current meters. J. Atmos. Oceanic Technol., 5, 340-352.

Kumar, P., and E. Foufoula-Georgiou, 1994: Wavelet analysis in geophysics: An introduction. Wavelets in Geophysics, E. Foufoula-Georgiou and P. Kumar, Eds., Academic Press, 1-43.

Liu, P. C., 2000a: Is the wind wave frequency spectrum outdated. Ocean Eng., 27, 577-588.

- 2000b: Wave grouping characteristics in nearshore Great Lakes. Ocean Eng., 27, 1221-1230.

Long, R. B., 1980: Statistical evaluation of directional spectrum estimates derived from pitch/roll buoy data. J. Phys. Oceanogr., 10, 944-952.

—_, and K. Hasselmann, 1979: Variational technique for extracting directional spectra from multicomponent wave data. $J$. Phys. Oceanogr., 9, 373-381.

Longuet-Higgins, M. S., D. E. Cartwright, and N. D. Smith, 1963: Observations of the directional spectrum of sea waves using the motions of a floating buoy. Ocean Wave Spectra; Proceedings of a Conference, Prentice-Hall, 111-136.

Lygre, A., and H. E. Krogstad, 1986: Maximum entropy estimation of the directional distribution in ocean wave spectra. $J$. Phys. Oceanogr., 16, 2052-2060.

MacPherson, J. I., R. Dobosy, S. Verma, W. P. Kustas, J. H. Prueger, and A. Williams, 1999: Intercomparisons between flux aircraft and towers in SGP97. Preprints, 14th Conf. on Hydrology, Dallas, TX, Amer. Meteor. Soc., 125-128.

Mourad, P. D., D. R. Thompson, and D. C. Vandemark, 2000: Extracting fine-scale winds from synthetic aperture radar images of the ocean surface. Johns Hopkins APL Tech. Digest, 21, 108-115.
Oltman-Shay, J., and R. T. Guza, 1984: A data-adaptive ocean wave directional-spectrum estimator for pitch and roll type measurements. J. Phys. Oceanogr., 14, 1800-1810.

Pawka, S. S., 1983: Island shadows in wave directional spectra. $J$. Geophys. Res., 88, 2579-2591.

Sun, J., D. Vandemark, L. Mahrt, D. Vicker, T. Crawford, and C Vogel, 2001: Momentum transfer over the coastal zone. $J$. Geophys. Res., 106, 12 437-12 448.

Torrence, C., and G. P. Compo, 1998: A practical guide to wavelet analysis. Bull. Amer. Meteor. Soc., 79, 61-78.

Trevorrow, M. V., and I. J. Booth, 1995: Extraction of ocean wave directional spectra using steerable Doppler side-scan sonars. J. Atmos. Oceanic Technol., 12, 1087-1100.

Vandemark, D., P. D. Mourad, T. L. Crawford, C. A. Vogel, J. Sun, S. A. Bailey, and B. Chapron, 2001: Measured changes in ocean surface roughness due to atmospheric boundary layer rolls. J. Geophys. Res., 106, 4639-4654.

Vogel, C. A., and T. L. Crawford, 1999: Exchange measurements above the air-sea interface using an aircraft. Air-Sea Exchange: Physics, Chemistry and Dynamics, G. L. Geernaert, Ed., Kluwer Academic, 231-245.

Walsh, E. J., D. W. Hancock, D. E. Hines, R. N. Swift, and J. F. Scott, 1985: Directional wave spectra measured with surface contour radar. J. Phys. Oceanogr., 15, 566-592.

,,,--- , and,- 1989 : An observation of the directional wave spectrum evolution from shoreline to fully developed. J. Phys. Oceanogr., 19, 670-690.

Wyatt, L. R., 1995: The effect of fetch on the directional spectrum of Celtic Sea storm waves. J. Phys. Oceanogr., 25, 15501559. 